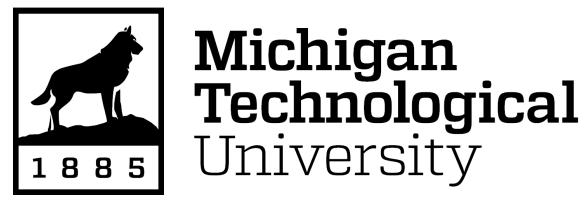

Michigan Technological University Digital Commons @ Michigan Tech

Dissertations, Master's Theses and Master's Reports

2017

\title{
ANALYSIS OF ALEKS MATHEMATICS PLACEMENT TEST DATA
}

Teresa Woods

Michigan Technological University, tmthomps@mtu.edu

Copyright 2017 Teresa Woods

\section{Recommended Citation}

Woods, Teresa, "ANALYSIS OF ALEKS MATHEMATICS PLACEMENT TEST DATA", Open Access Master's Report, Michigan Technological University, 2017.

https://doi.org/10.37099/mtu.dc.etdr/393

Follow this and additional works at: https://digitalcommons.mtu.edu/etdr

Part of the Educational Assessment, Evaluation, and Research Commons 


\section{ANALYSIS OF ALEKS MATHEMATICS PLACEMENT TEST DATA}

By

Teresa Woods

\section{A REPORT}

Submitted in partial fulfillment of the requirements for the degree of MASTER OF SCIENCE

In Mathematical Sciences

MICHIGAN TECHNOLOGICAL UNIVERSITY

2017

(C) 2017 Teresa Woods 
This report has been approved in partial fulfillment of the requirements for the Degree of MASTER OF SCIENCE in Mathematical Sciences.

Department of Mathematical Sciences

$\begin{array}{ll}\text { Report Co-Advisor: } & \text { Dr. Yeonwoo Rho } \\ \text { Report Co-Advisor: } & \text { Dr. Shari Stockero }\end{array}$

Committee Member: $\quad$ Dr. Todd King

Department Chair: $\quad$ Dr. Mark Gockenbach 


\section{Table of Contents}

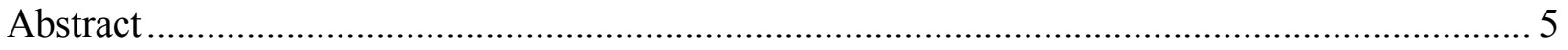

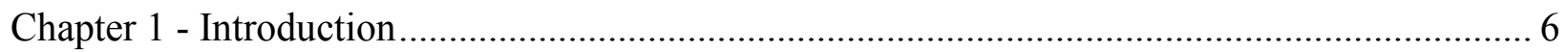

Chapter 2 - Literature Review............................................................................................. 9

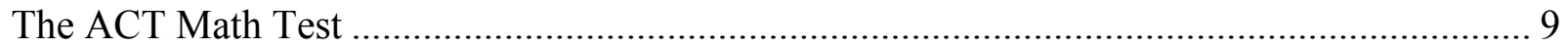

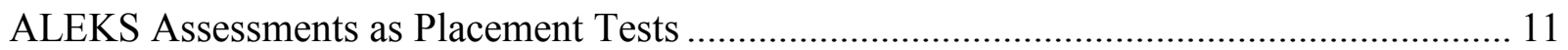

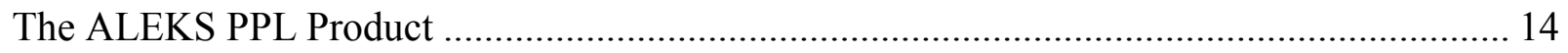

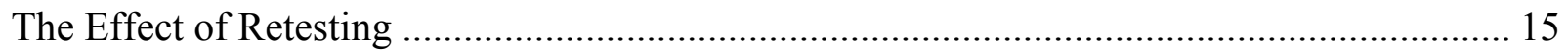

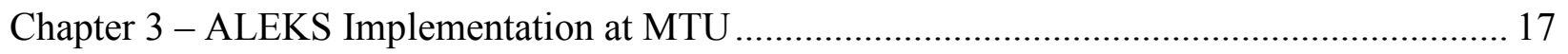

Chapter 4 - Data Collection and Preparation ……………............................................................. 19

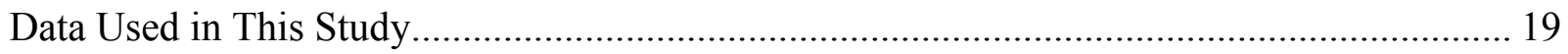

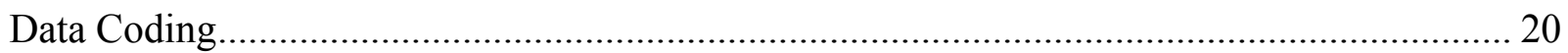

Chapter 5 - Cut Score Influence on Pass Rates .................................................................... 22

Conditional Probability Analysis ………………………...................................................... 22

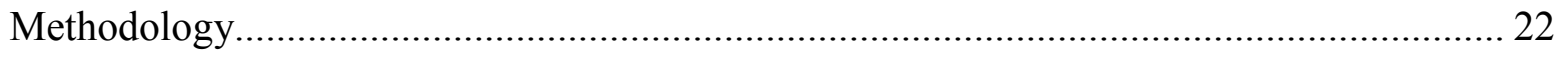

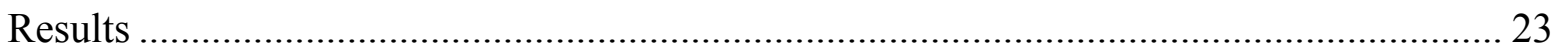

Final Course Grade Distribution by ALEKS Placement Test Score.......................................... 29

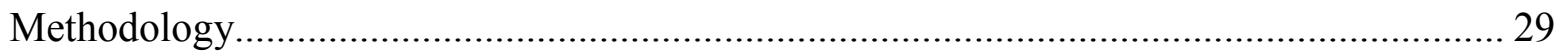

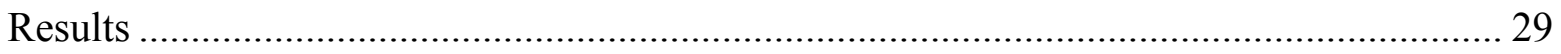

Chapter 6 - Influence of Path to Calculus I on Grades.............................................................. 33

Odds Ratios from Contingency Tables …………………………............................................ 33

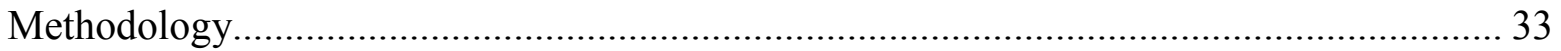

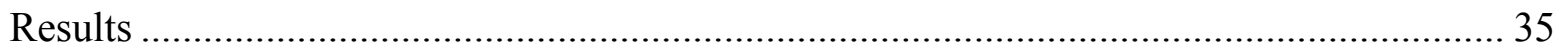

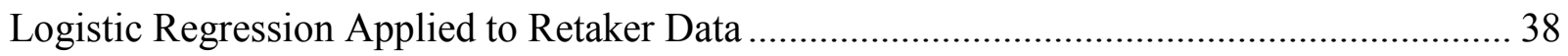




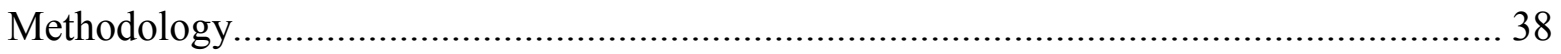

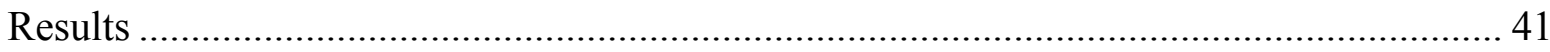

Chapter 7 - ALEKS Subscore Influence on Calculus I Performance ………………................... 45

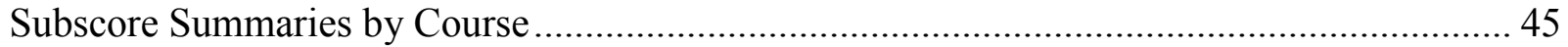

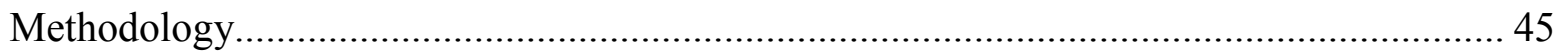

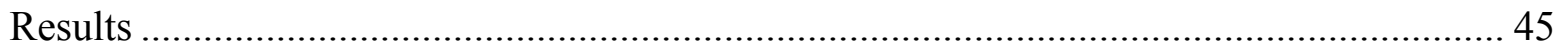

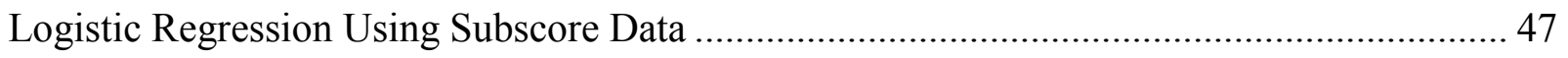

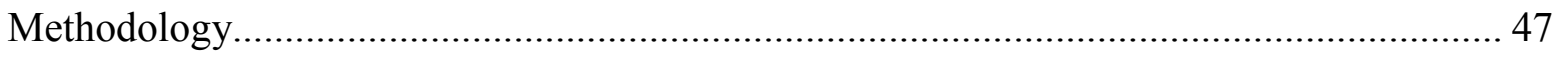

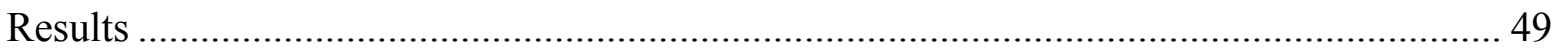

Chapter 8 - Discussion, Conclusions and Recommendations ..................................................... 52

Research Question 1: Cut Score Influence on Pass Rates ....................................................... 52

Research Question 2: Influence of Path to Calculus I on Grades .............................................. 55

Research Question 3: ALEKS Subscore Influence on Calculus I Performance ........................ 58

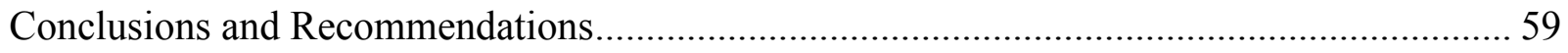

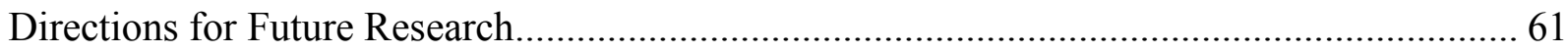

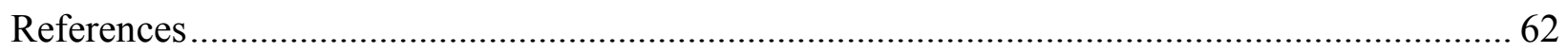

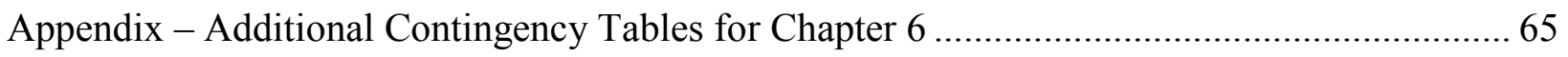




\begin{abstract}
In Fall 2014, Michigan Technological University (MTU) began using an online mathematics placement test provided by ALEKS Corporation. This study answers three questions that accompanied this implementation: (1) Do the cut scores being used for Precalculus and Calculus I result in the expected pass rates for those courses?, (2) Does the path by which a student becomes eligible for Calculus I - via a single placement test attempt, via multiple placement test attempts, or by beginning in Precalculus at MTU - influence their likelihood of success in Calculus I?, and (3) Does a mathematical background weak in any particular curriculum area correlate with a lower chance of success in Calculus I? ALEKS placement test scores, Calculus I exam scores, and Precalculus and Calculus I final grade data from students who took the ALEKS placement test during the 2015 testing cycle were examined. A conditional probability analysis indicated that the current cut scores result in a probability of a $\mathrm{C}$ grade or better of at least 0.64 in each course examined. Tabulation of DFW rates showed that students right at the cut score threshold have higher DFW rates than the overall rate for the course. Odds ratios revealed that students who placed into Calculus I on their first testing attempt were the most likely to receive a final grade of $\mathrm{C}$ or better. ALEKS subscore data indicated that most incoming students exhibited knowledge gaps in trigonometry. Logistic regression showed that a $1 \%$ increase in trigonometry subscore increased the odds of earning a $\mathrm{C}$ or better in Calculus I by $3 \%$.
\end{abstract}




\section{Chapter 1 - Introduction}

Michigan Technological University (MTU) is a public university located in Michigan's Upper Peninsula. The undergraduate enrollment in Fall 2015 was 5,721 students (Michigan Technological University Office of Institutional Analysis, 2016). More than 90 percent of those students were enrolled in a STEM (science, technology, engineering, mathematics) degree program, nearly all of which require at least one semester of college-level Calculus.

Beginning in Fall 2014, the MTU mathematics department changed its process for placing the majority of incoming students into their first mathematics course. It shifted from using the ACT math test score to using an online placement test provided by ALEKS (Assessment and Learning in Knowledge Spaces) Corporation. There were two reasons for this switch. The first was that most students had taken the ACT in their junior year of high school, meaning placement decisions were being made using information that may have been more than a year old. The second reason was that students who were dissatisfied with their placement did not have a convenient, focused way to remediate and retest (A. Humes, personal communication, May 12, 2016). The ALEKS product, in addition to supporting retesting at the user's convenience, is accompanied by optional remediation software.

Many questions accompanied the implementation of the ALEKS placement test. What should the cut scores be for placement into particular courses? How many retakes should a student be permitted? How many hours of remediation should be required before a retake? While ALEKS Corporation helps customers choose initial settings for these parameters, it seemed that it would be helpful to confirm those settings with local data. That desire was the impetus for this study. Furthermore, the overall score for each ALEKS test attempt is accompanied by eleven 
curriculum area specific subscores. This level of information was not available with the ACT scores formerly used to guide placements. Its existence sparked additional questions about the utility of the dataset for possibly improving placement and/or instruction.

This report summarizes the findings of a statistical investigation aimed at answering the questions posed above. Specifically, the study was organized around the following research questions:

1. Do the ALEKS cut scores being used for Precalculus and Calculus I placement at MTU result in the expected pass rates for those courses?

2. How do Calculus I course grades of the following groups compare to one another?

- Students who achieved Calculus I placement on their first ALEKS placement test attempt

- Students who achieved Calculus I placement on their second or third ALEKS placement test attempt (after completing remediation exercises in ALEKS)

- Students who are placed into Precalculus their first semester at MTU, and then enroll in Calculus I the following semester

3. Does a lack of incoming proficiency in any particular curriculum area for which the ALEKS placement test provides a subscore correlate with a decreased likelihood of successful course performance?

The methodology and results pertinent to each of these research questions appear in Chapters 5-7 of this report. Chapter 2 contains a review of the literature related to mathematics placement testing, in particular placement mechanisms employing a student's ACT math score or ALEKS score. Chapter 3 describes how MTU uses ALEKS to determine first mathematics course placement. Chapter 4 describes the data used in this study, and how that data was 
prepared for analysis. A discussion of results, conclusions, recommendations, and possible directions for future research are presented in Chapter 8. 


\section{Chapter 2 - Literature Review}

The mechanism that a university uses to determine first year mathematics placement warrants careful selection and monitoring. Overplacement, which describes placing a student into a course for which they are not adequately prepared, may adversely impact retention. In fact, a study conducted at Boise State University indicated that the grade earned in a student's first college level mathematics class was significantly correlated to whether the student persisted in engineering, while the level at which they began mathematics study at the university was not correlated to persistence (Gardner, Pyke, Belcheir, \& Schrader, 2007). Underplacement, which describes placing a student into a mathematics course for which they are overqualified, may increase the time required to graduate, or tuition costs, or both. An ideal mathematics course placement mechanism would eliminate concerns about overplacement and underplacement. Such a perfect tool does not yet exist, but commercial product developers and higher education institutions have expended a great deal of effort trying to identify mechanisms that reliably recommend appropriate placement most of the time. ACT is one such developer, and ALEKS Corporation is another. The sections that follow describe the mathematics placement testing tools offered by each of these organizations.

\section{The ACT Math Test}

In 2011, the National Assessment Governing Board surveyed a nationally representative sample of 1,560 public and private 2-year and 4-year institutions regarding their use of tests and cut scores in math course placement decisions (Fields \& Parsad, 2012). Specifically, this survey asked respondents how their institution assessed readiness for an entry-level credit-bearing college math course (presumably college algebra). Seventy-one percent of the institutions 
surveyed reported using a test of some kind. Six nationally available standardized tests were consistently mentioned by survey respondents. The ACT math test was the most common among those tests, used by 23 percent of respondents.

Historically, the only math course that ACT published a College Readiness Benchmark score for was college algebra (ACT, n.d.). According to ACT, a score of 22 on the ACT math test represents the level of achievement required for a student to have a $50 \%$ chance of receiving a B or higher or about a $75 \%$ chance of receiving a $\mathrm{C}$ or higher in college algebra. Having the ACT research team's stamp of approval behind this readiness metric may be one reason why the ACT math test is so commonly used for placement.

It is important to recognize that until 2015 , ACT made no claims regarding a score on the ACT math test that could be expected to correlate with success in Calculus $\mathrm{I}^{1}$. This did not prevent some schools, including MTU, from using the ACT math test scores to gate keep Calculus I placement, with local data providing a means of setting cut scores. The Mathematical Association of America's (MAA's) recent study Characteristics of Successful Programs in College Calculus--the first nationwide investigation of college-level Calculus I in the United States to combine both large-scale survey data and in-depth case study analysis-- offers an estimate of how widespread this practice was (Hsu \& Bressoud, 2015). The 2010 study, in which the MAA selected a stratified random sample of non-profit colleges and universities offering a degree in mathematics (Associate's, Bachelor's, Master's, or Doctoral) found that among

\footnotetext{
${ }^{1}$ In 2015, ACT added a STEM (science, technology, engineering, mathematics) score to student score reports, along with a corresponding benchmark (ACT, 2015). The STEM score is derived from the ACT mathematics and science scores. The benchmark was developed by combining typical grades in first-year college STEM courses (Calculus, General Biology, General Chemistry, and Physics) into a single course success model to determine the ACT STEM test score that was associated with at least a $50 \%$ chance of earning a $\mathrm{B}$ or higher or a $75 \%$ change of earning a $\mathrm{C}$ or higher in those courses. The resulting ACT STEM College Readiness Benchmark score is 26.
} 
institutions most similar to MTU (universities which offered a Doctoral degree in mathematics), 50 percent had mandatory placement tests, 22 percent had non-mandatory placement tests, and 28 percent had no placement test. Within the group that used placement tests, a test created by the department was most common (64 percent), ALEKS was the second most common (10 percent) and ACT or SAT was utilized by 5 percent.

\section{ALEKS Assessments as Placement Tests}

ALEKS is a relative newcomer to the mathematics placement testing arena, but the results of the MAA's study (Hsu \& Bressoud, 2015) suggest it is quickly gaining acceptance. The product is a commercial implementation of knowledge space theory (KST) (Falmagne \& Doble, 2013). According to this theory, a student's competence in a subject (such as precalculus) at a given instant may be identified with a knowledge state-a precise depiction of what the student knows and does not know at a given moment. A knowledge space is the set of all possible knowledge states. ALEKS assessments were not initially designed as placement examinations. They were part of an adaptive learning system in which an initial assessment of a student's knowledge was used to calibrate the system in such a way that it could provide a customized learning experience. Due to the adaptive nature of the product and its ordered structure that captures the dependence between items, ALEKS can assess students' proficiencies on knowledge domains containing 200-300 mathematical items with just 30 questions (Harper \& Reddy, 2013). An example of a mathematical item is finding the roots of a quadratic equation (Falmagne \& Doble, 2013).

A 2005 study done at Louisiana Tech University compared the success of an ACT math score versus an ALEKS assessment score for predicting successful Calculus I course completion 
(Carpenter \& Hanna, 2006). Historical data from the university supported a cut score of 26 on the ACT math test to allow Calculus I placement. The data showed that the majority of students passed the course on their first try if their score was at least this good. In 2001, the university began using ALEKS for online mathematics tutoring, making it a mandatory course component for everyone who enrolled in Calculus I. After a few years of use, some at the university became curious as to whether performance on the initial ALEKS assessment might be a better predictor of Calculus I performance than the ACT math score, or if a combined score might be the optimal metric for course placement. After all, the initial assessment was designed to measure mastery of prerequisite course material and course content for the course in which the student was enrolled. After conducting a statistical analysis using Calculus I course grades from Fall 2005, they observed that the ALEKS initial assessment score was a clearer indicator of Calculus I readiness than the ACT math score.

Aware of Louisiana Tech University's encouraging experience with ALEKS, the University of Illinois began to explore ALEKS as a placement tool. With testing that began in summer 2007, they were the first institution to use ALEKS in an assessment mode (separate from the learning mode) to guide mathematics course placement. Their placement program focused on four courses: Preparation for Calculus, Business Calculus, Calculus I, and Calculus I for students with experience. Placement decisions were made using the total percentage of concepts demonstrated by a student (curriculum area specific subscores were not used for placement purposes). To incentivize participation during the launch year, completion of the unproctored ALEKS placement exam by the end of the add/drop cycle constituted 10 percent of the student's grade in the upcoming course, all or nothing. Unlimited attempts were permitted, as 
was ALEKS-based or other means of remediation. Initial cut scores on the ALEKS assessment were 40 for Preparation for Calculus and Business Calculus and 60 for Calculus I (both versions). For the second year and beyond, cut scores were set at 50 and 70, respectively, because the data indicated these scores would be more effective in reducing overplacement. During the launch year, placement scores were recommended to students but were not rigidly enforced. It was assumed that students who did not achieve the target score would self-select into a lower level course. In the second and later years, the University of Illinois made completion of the placement exam at a specified level a prerequisite for enrolling in a mathematics course (Reddy \& Harper, 2013a).

After implementation of the ALEKS-based placement program at the University of Illinois, course withdrawals were dramatically reduced relative to Fall 2006. In Business Calculus and both Calculus I courses, the number of DFW (D+, D, D-, F, or withdrawal) student grades averaged in 2007 and 2008 was lower than in 2006 (Preparation for Calculus was first offered in Spring 2007 and thus cannot be compared similarly) (Reddy \& Harper, 2013a). Data from the placement program in the years 2008-2010 indicated that initial student assessments in ALEKS correlated well with course grades in all courses examined, and the correlation was a significant improvement over the university's former placement method, the ACT math exam score (Reddy \& Harper, 2013b).

In Fall 2008, Boise State University implemented an ALEKS mathematics placement strategy very similar to that used by the University of Illinois, using cut scores of 40 for Precalculus and 70 for Calculus I (Bullock \& Callahan, 2009). The incentive for students to achieve these scores by the end of the add/drop period was the same as that used by the 
University of Illinois, under the same assumption that students would self-select into a lower course if they were unable to achieve the cut score. Both the University of Illinois and Boise State University saw only $1-2 \%$ of students remain in mathematics courses for which their best ALEKS score indicated they were underqualified. Before ALEKS, placement decisions at Boise State University were made using a variety of scores, including ACT and SAT math scores, AP Calculus AB exam scores, and COMPASS examination scores. Both Precalculus and Calculus I pass rates improved after the ALEKS implementation described above became a course requirement. It was likely in response to the growing popularity of ALEKS assessments being used as placement tests that in 2012 ALEKS Corporation made available its PPL (Placement, Preparation, and Learning) product to serve specifically as a placement mechanism (ALEKS Corporation, n.d.-a).

\section{The ALEKS PPL Product}

In addition to a placement test, the PPL product also provides an easily accessed online remediation environment, the Prep and Learning Module. If this product is accessed in learning mode, where remediation takes place, it contains 314 topics distributed across curriculum areas as shown in Table 1 below (UC Regents and ALEKS Corporation, 2012). The assessment used for mathematics placement asks approximately 30 questions. The adaptive nature of the product creates variation in assessment length between attempts. The result is an overall placement test score accompanied by subscores for each of the curriculum areas listed in Table 1. 
Table 1

Number of Items Per Curriculum Area in ALEKS PPL Product

\begin{tabular}{lc}
\hline \multicolumn{1}{c}{ Curriculum Area in ALEKS } & Number of Topics \\
\hline Whole Numbers, Fractions, and Decimals & 37 \\
Percents, Proportions, and Geometry & 32 \\
Signed Numbers, Linear Equations and Inequalities & 53 \\
Lines and Systems of Linear Equations & 27 \\
Relations and Functions & 22 \\
Integer Exponents and Factoring & 30 \\
Quadratic and Polynomial Functions & 21 \\
Rational Expressions and Functions & 23 \\
Radicals and Rational Exponents & 20 \\
Exponentials and Logarithms & 20 \\
Trigonometry & 29 \\
\hline
\end{tabular}

\section{The Effect of Retesting}

Whether referring to ALEKS PPL or earlier product offerings from the company, the results typically reported in the literature do not in any way characterize student performance according to the number of times the student took the placement test, although permitting multiple attempts is common. At the time of this writing, the author was only able to locate one study that connected number of attempts to performance. Adaricheva and Assylbekov (2013) reported their findings related to using ALEKS to determine Calculus I placement at Nazarbayev University in the Republic of Kazakhstan. In their implementation, all testing was proctored. A 
retake was permitted a week after the initial test attempt, but only after 5 hours of practice in the ALEKS remediation environment. In the vast majority of cases, they found that the scores of students increased between their first attempt and second attempt. They then offered a third test attempt at two different points in time: one seating was ten days after the second attempt, and the other seating was approximately three months after the second attempt. Three hours of practice were required between the second and third attempts. Their results showed that most students who took the test a third time ten days after their second attempt improved their scores again, while those who waited three months essentially returned to the same level of competence indicated by their first attempt. From these results, Adaricheva and Assylbekov concluded that students progressively master precalculus skills by practicing in the ALEKS Prep and Learning Module between testing attempts, so long as those attempts are not spaced too far apart. One aim of the current study is to learn more about retesting and its relationship to later course performance. 


\section{Chapter 3 - ALEKS Implementation at MTU}

MTU currently uses the ALEKS PPL product to determine mandatory placements for the majority of incoming students in their first mathematics course. Exceptions to this policy are students with college transfer credit in college algebra or higher, or with acceptably high AP Calculus, IB Higher Level Mathematics, CLEP Precalculus or CLEP Calculus exam scores (Michigan Technological University, n.d.). The ALEKS test is administered over the Internet without a proctor. Each ALEKS test attempt has a 24 hour time limit.

The mathematics placement test portal is open to students from May 1 through June 30 of each year. Table 2 shows the cut scores on the ALEKS test used for placement in various courses (Michigan Technological University, n.d.).

Table 2

ALEKS Mathematics Placement Test Cut Scores Used in Fall 2015

\begin{tabular}{lc}
\hline \multicolumn{1}{c}{ First Semester Mathematics Course } & Required ALEKS Placement Test Score \\
\hline MA1030 College Algebra & Score of 40 or higher recommended. \\
MA1032 Precalculus & 56 or higher \\
MA1161 Calculus Plus with Technology I & 70 or higher \\
MA1160 Calculus with Technology I & 80 or higher \\
\hline Note. Placement by other means, such as AP test scores, was possible. \\
See http://www.mtu.edu/math/placement/recommended/.
\end{tabular}


If the result of their first placement test attempt places a student into a lower level mathematics course than they had hoped, they may retake the assessment after spending a minimum of 3 hours in the ALEKS Prep and Learning Module. If the second score is also unsatisfactory to the student, they may take the assessment a third time, but only after spending at least 3 more hours in the Prep and Learning Module. 


\section{Chapter 4 - Data Collection and Preparation}

\section{Data Used in This Study}

The population investigated in this study consisted of MTU students who had taken the ALEKS PPL mathematics placement test during the 2015 testing cycle and then enrolled in one of the following courses in Fall 2015:

- Precalculus (MA1032)

- Calculus Plus with Technology I (MA1161, 5 credits, 4 meetings per week)

- Calculus with Technology I (MA1160, 4 credits, 3 meetings per week)

The MA1161 and MA1160 courses cover the same content and all sections of the courses use a common exam at all testing points within the semester.

The following three datasets were obtained for the study population:

- ALEKS placement test results, including curriculum area subscores and overall scores for each of up to three placement test attempts

- Midterm and final exam grades from MA1032, MA1161, and MA1160

- Final course grades from MA1032, MA1161, and MA1160

For students who completed MA1032 in Fall 2015 followed by MA1161 in Spring 2016 (MA1160 is not offered in the spring), the MA1161 exam and final course grades from Spring 2016 were gathered as well. The datasets were then combined to provide one to three records for each student, after which the records were anonymized. Multiple records for a student indicated the student had taken the ALEKS mathematics placement test multiple times. 


\section{Data Coding}

To prepare the data for analysis techniques that require a binary outcome, exam grades of 70 percent or higher were coded as satisfactory. Non-zero exam grades below 70 percent were coded as unsatisfactory. Exam grades of zero were not used in the study, since a zero score could indicate a missing grade. Final course grades of $\mathrm{C}$ or better were coded as satisfactory. Final course grades of CD, D, and F were coded as unsatisfactory. Unless otherwise indicated, W grades were not used in the study because of the range of reasons for which students withdraw from courses (not all related to difficulty with the material). For each part of the study, the maximum usable sample size was analyzed. For example, if a student completed the first midterm exam and then dropped the course, their record would have been included in analyses restricted to the first exam, but omitted from analyses of grades issued later in the course.

In cases where a student attempted the ALEKS placement test more than once, two more fields were added to their record. The first field, "interval" described the range of ALEKS placement test scores which included the student's score. These intervals, defined in Table 3, were set based on the most rigorous math course the student would qualify for with that score.

Table 3

ALEKS Mathematics Placement Test Score Interval Definitions

\begin{tabular}{ccc}
\hline Interval & $\begin{array}{c}\text { Range of ALEKS } \\
\text { Placement Test Scores }\end{array}$ & $\begin{array}{c}\text { Calculus Sequence Course } \\
\text { Qualification }\end{array}$ \\
\hline 1 & {$[0,55]$} & College Algebra \\
2 & {$[56,69]$} & MA1032 but no higher \\
3 & {$[70,79]$} & MA1161 but not MA1160 \\
4 & {$[80,100]$} & MA1160 \\
\hline
\end{tabular}


The intervals described in Table 3 were then used to define a second field, "jump type," which describes movement from one interval to another as a result of retesting. During this study, it was observed that all retake attempts were non-decreasing in terms of intervals. That is, subsequent test scores achieved by a student either occupied the same interval as the first attempt, or occupied a higher interval. For students with three placement test attempts on record, the jump type flag was assigned by considering the lowest interval and the highest interval (thus interval patterns of $(1,1,3)$ and $(1,2,3)$ would be coded the same as a $(1,3)$ record for a student with two placement test attempts). These groupings were made to avoid extremely small sample sizes. The jump type flags are defined in Table 4. They facilitated the grouping of students to investigate Research Question 2.

Table 4

ALEKS Mathematics Placement Test Score Jump Type Definitions

\begin{tabular}{cc}
\hline Jump Type & Interval Movement $($ From $\rightarrow$ To $)$ \\
\hline N & No change \\
A & $1 \rightarrow 2$ \\
B & $2 \rightarrow 3$ \\
C & $3 \rightarrow 4$ \\
D & $1 \rightarrow 3$ \\
E & $2 \rightarrow 4$ \\
F & $1 \rightarrow 4$ \\
\hline
\end{tabular}




\section{Chapter 5 - Cut Score Influence on Pass Rates}

The first research question asked, "Do the ALEKS cut scores being used for Precalculus and Calculus I placement at MTU result in the expected pass rates for those courses?" Two analysis techniques were used to investigate this question. The first technique explored the probability of receiving a satisfactory or unsatisfactory final course grade, given a placement test score above or below a particular pivot score. The second technique examined DFW (D, F, withdrawal) rates by placement test score range. Below, a detailed explanation of each methodology is followed immediately by the corresponding results.

\section{Conditional Probability Analysis}

\section{Methodology}

In the first analysis, final grades which had been coded as satisfactory ( $\mathrm{C}$ or better) or unsatisfactory $(\mathrm{CD}, \mathrm{D}$, or $\mathrm{F})$ were used to compute two conditional probabilities:

- that of a student receiving a satisfactory final grade in their Fall 2015 mathematics course, given that their highest placement test score was at or above a particular value (a pivot),

$$
P(\text { Satisfactory } \mid \text { Score } \geq \text { Pivot })=\frac{P(\text { Satisfactory and Score } \geq \text { Pivot })}{P(\text { Score } \geq \text { Pivot })}
$$

where $P($ Score $\geq$ Pivot $)$ indicates the probability that a randomly chosen student's highest placement test score was at or above a certain pivot; and

- that of a student receiving an unsatisfactory final grade in their Fall 2015 mathematics course, given that their highest placement test score was below a pivot,

$$
P(\text { Unsatisfactory } \mid \text { Score }<\text { Pivot })=\frac{P(\text { Unsatisfactory and Score }<\text { Pivot })}{P(\text { Score }<\text { Pivot })}
$$


where $P($ Score $<$ Pivot $)$ indicates the probability that a randomly chosen student's highest placement test score was below a certain pivot.

This analysis was done to verify that the first of these probabilities increases as the pivot increases (i.e., a higher placement test score results in a higher probability of receiving a satisfactory final grade), and that the second decreases as the pivot increases (i.e., a higher placement test score results in a lower probability of receiving an unsatisfactory final grade). Once that verification was made, if the probabilities computed at the cut score pivots were considered too low or too high, this analysis could inform the choice of a new cut score.

\section{Results}

MA1032: Precalculus. Figure 1 shows the probability of earning a final course grade of C or better in MA1032, given a placement test score greater than or equal to a given pivot. In this figure, and in Figures 3 and 5 that follow, the number of scores greater than or equal to a particular pivot is plotted on the secondary (right) axis to convey population size. Recall that the cut score for MA1032 was 56. The highest placement test score among those who enrolled in MA1032 in Fall 2015 was 92. Students with scores above 69 would be considered overqualified for this course since a score of 70 would qualify them for MA1161, and a score of 80 would qualify them for MA1160. Figure 1 shows that when the population is relatively large, say for scores between 56 and 69, the expected increasing trend is observed. Deviations from this trend are attributed to small population size for scores of 70 and above. If the small population results are ignored, in general students who achieved the cut score of 56 or greater had at satisfactory final grade probability of at least 0.72 . 


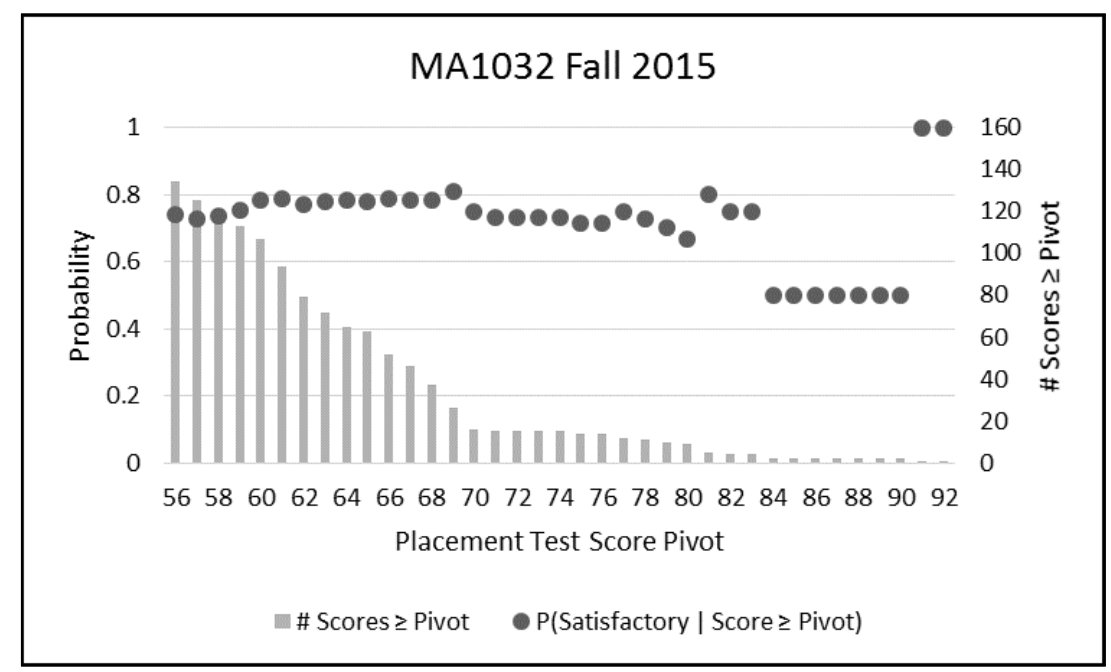

Figure 1. Conditional probability of satisfactory MA1032 final course grade.

Figure 2 shows the probability of a student earning a final MA1032 course grade of CD, $\mathrm{D}$, or F, given a placement test score less than the indicated pivot. In this figure and in Figures 4 and 6 , the number of scores less than a particular pivot is given to convey population size. For unknown reasons, six students were enrolled in the course with placement test scores less than 56. The data from these students are included in the probability and count at the 57 pivot. Once the population size grew to 33 (placement score of 60), the observed trend is decreasing as expected. 


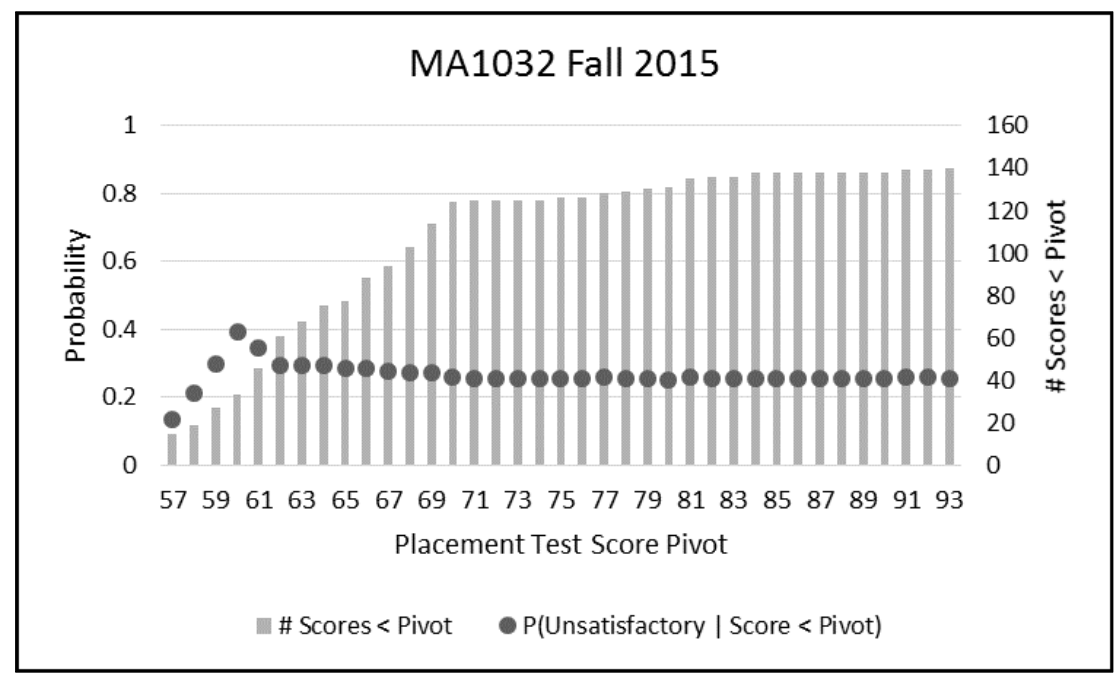

Figure 2. Conditional probability of unsatisfactory MA1032 final course grade.

MA1161: Calculus Plus with Technology I. Figures 3 and 4 represent the same type of analysis, this time done for MA1161. Figure 3 shows the probability of earning a final course grade of $\mathrm{C}$ or better, given a placement test score greater than or equal to the indicated pivot. The minimum placement test score required to qualify a student for MA1161 was 70. The highest placement test score among those who enrolled in MA1161 Fall 2015 was 94. Students with scores above 79 would be considered overqualified for this course, as they qualified for MA1160. The trend that appears in Figure 3 is mostly increasing, as expected. Students who achieved the MA1161 cut score of 70 or greater had a satisfactory final grade probability of at least 0.64 . 


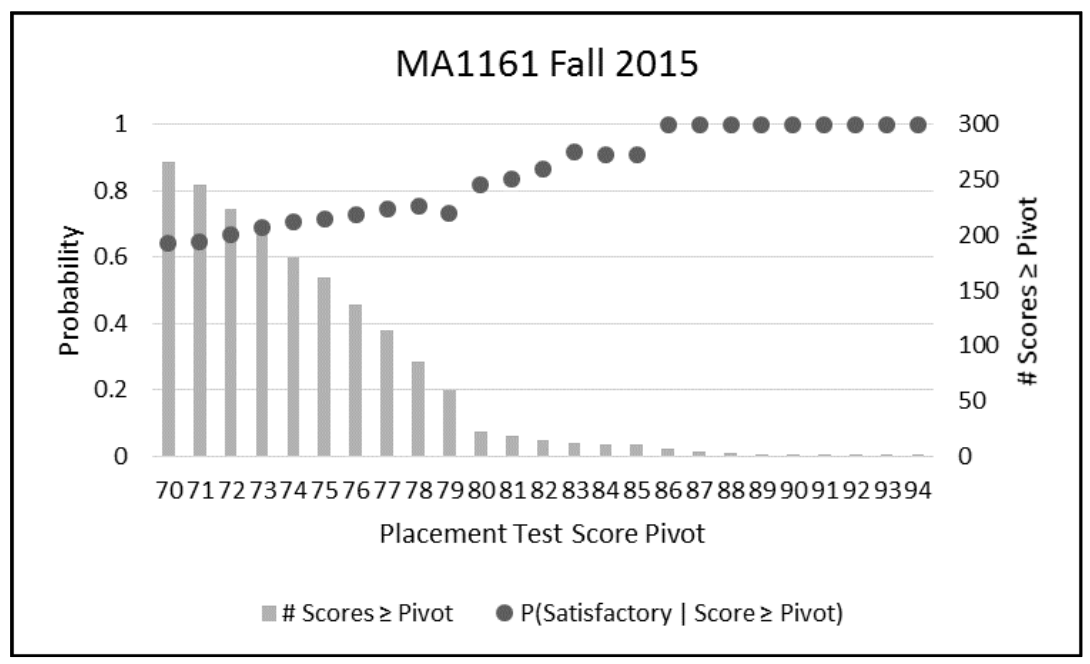

Figure 3. Conditional probability of satisfactory MA1161 final course grade.

Figure 4 shows the probability of earning a final MA1161 grade of CD, D, or F, given a placement test score less than the indicated pivot. Once again for unknown reasons, five students were enrolled in the course with placement test scores less than the required 70 . The data from these students are included in the probability and count reported at the 71 pivot. With the exception of the probability at this pivot, which is computed from the smallest number of scores, the trend that appears in Figure 4 is what one would expect. 


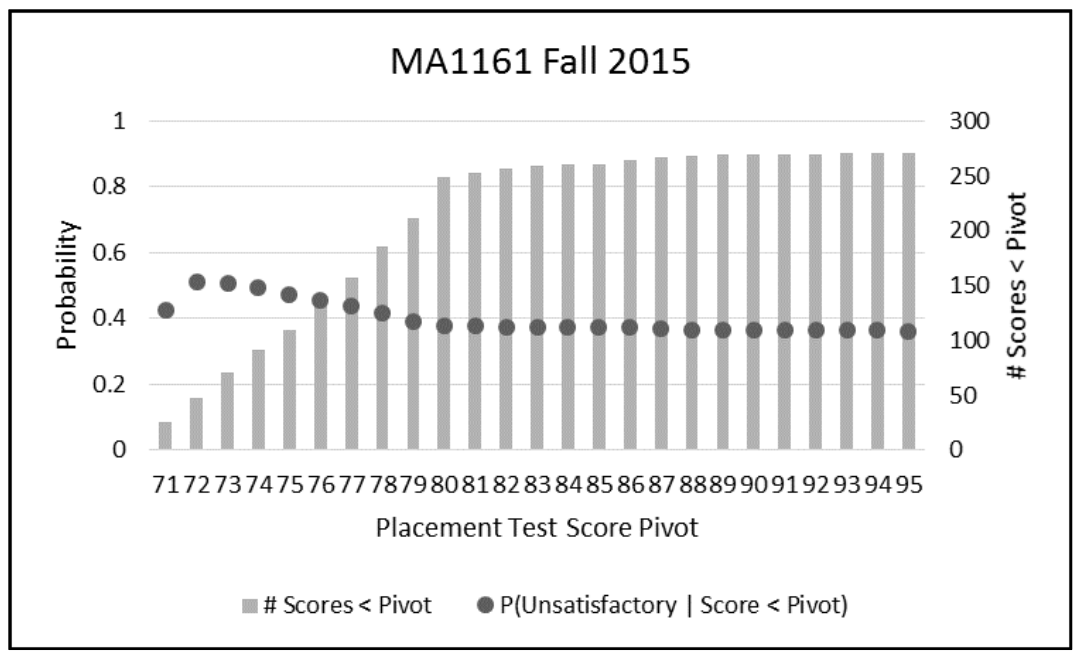

Figure 4. Conditional probability of unsatisfactory MA1161 final course grade.

MA1160: Calculus with Technology I. Figures 5 and 6 complete the first analysis, representing results from MA1160. Recall that this course had a cut score of 80 required for entry. Figure 5 shows the probability of earning a final course grade of $\mathrm{C}$ or better in MA1160, given a placement test score greater than or equal to the indicated pivot. The highest placement test score among those who enrolled in MA1160 Fall 2015 was 97. Figure 5 shows a cluster of low satisfactory course performance probabilities that one would not expect for placement scores higher than 91 . Only eighteen students had scores in this range, so it is possible that these outliers are the result of a small population size. If results computed on small populations are overlooked, students who achieved the MA1160 cut score of 80 or greater had a satisfactory final grade probability of at least 0.79 . 


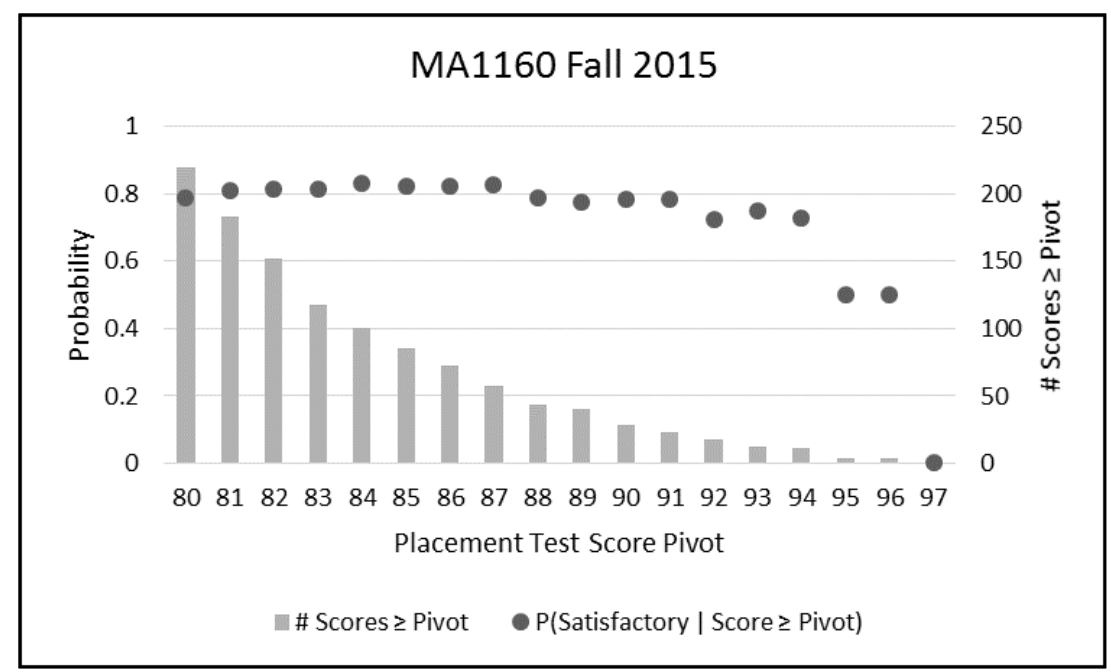

Figure 5. Conditional probability of satisfactory MA1160 final course grade.

Finally, Figure 6 shows the probability of earning a final grade of CD, D, or F in MA1160, given a placement test score less than the indicated pivot. Six students whose highest placement test scores were less than the required 80 completed the course. The data from these students are included in the probability and count reported at the 81 pivot. The decreasing trend in probabilities as the pivot increases is as expected.

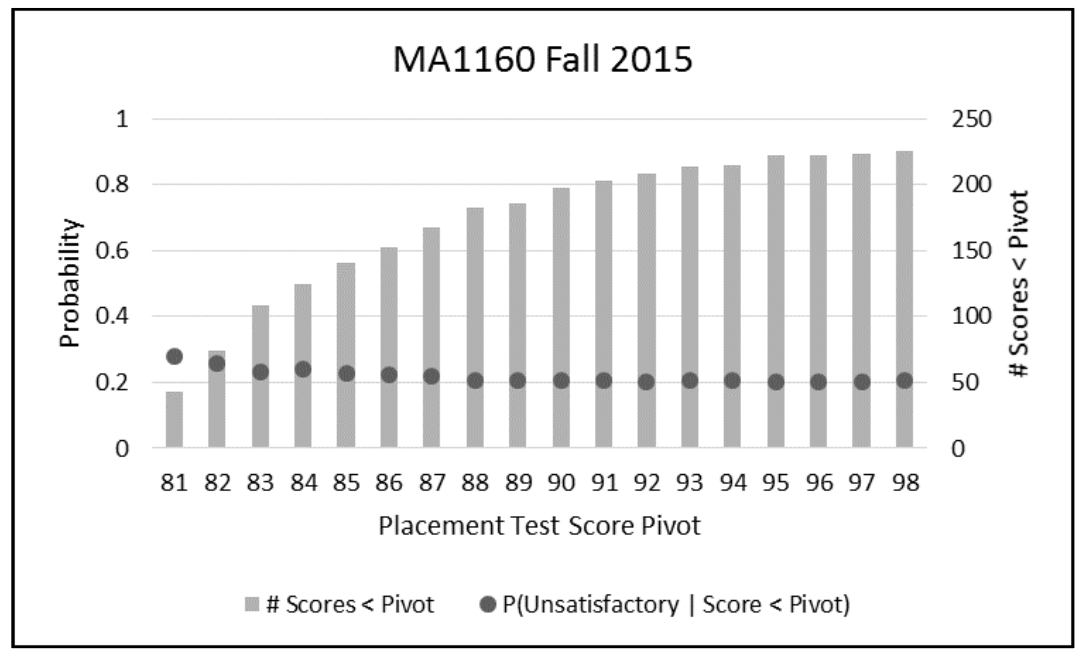

Figure 6. Conditional probability of unsatisfactory MA1160 final course grade. 


\section{Final Course Grade Distribution by ALEKS Placement Test Score}

\section{Methodology}

The second technique used to investigate Research Question 1 was calculation of DFW rates by course and by ALEKS placement test score range. Each column in the stacked bar graphs that follow represents the Fall 2015 final course grade distribution of students in the indicated course within the ALEKS placement test score range noted on the horizontal axis.

\section{Results}

Figure 7 shows the grade distribution for MA1032. The ranges begin with the cut score for MA1032, which was 56. The rightmost bar represents overqualified students. Their placement test scores were sufficient for MA1161, perhaps even MA1160. The other ranges were set to distribute scores somewhat evenly. The overall DFW rate for MA1032 in Fall 2015 was $18 \%$. This includes the six students whose placement test scores were below 56 . Among students with placement test scores in the 56-60 range, the DFW rate was markedly higher at $25 \%$. Nine of the forty students in this group received failing final grades (none withdrew). 


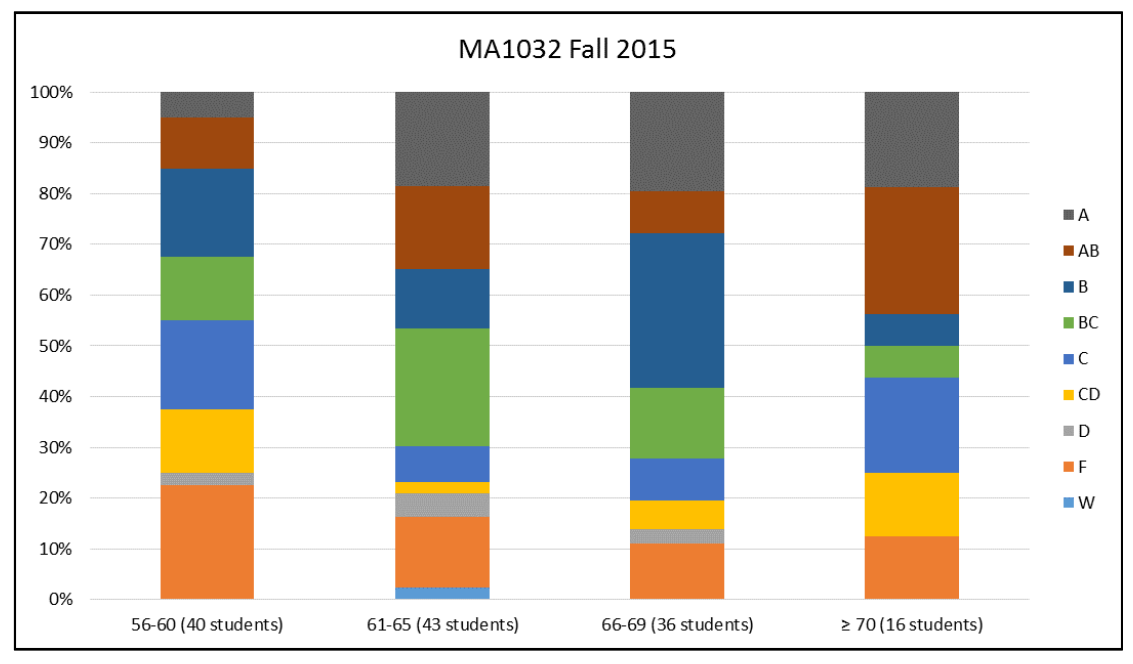

Figure 7. MA1032 final course grade distribution by placement test score range.

Figure 8 shows a similar analysis for MA1161, which had a cut score of 70 . Once again, the rightmost bar represents overqualified students and the remaining ranges were set to distribute scores evenly. The overall DFW rate for MA1161 Fall 2015 was 31\%. This included 6 students whose placement test scores were less than the cut score of 70 for this course (one of those students withdrew, explaining why this group size increased from the conditional probability analysis presented earlier in this chapter). The subgroup of students with placement test scores between 70 and 72 had the highest DFW rate for this course at $41 \%$. Eighteen students with scores in this range failed the course, and four withdrew. At the upper end of the placement test score range for which a student would be placed in MA1161 (78-79), the DFW rate was $26 \%$. 


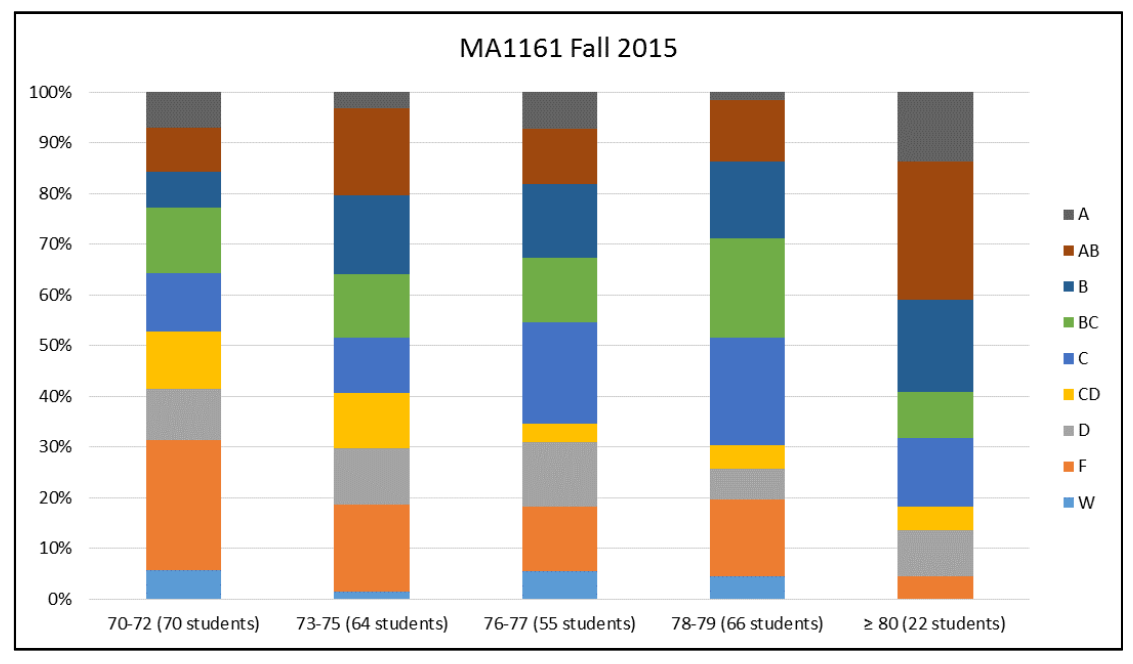

Figure 8. MA1161 final course grade distribution by placement test score range.

Figure 9 represents the same analysis for MA1160, which had a cut score of 80 . This time there is no significance to the range describing the rightmost bar, since this is the most rigorous course for which the ALEKS placement test is used. The overall DFW rate for MA1160 in Fall 2015 was $17 \%$. This included 6 students whose placement test scores were less than the cut score. Among students with placement test scores of $80-81$, the rate was $22 \%$. At the other end of the spectrum, among students with placement test scores of 92 or higher, the DFW rate was $32 \%$. This surprising result may be attributed to the relatively small sample size of 19 . Within this group of nineteen students, one $\mathrm{W}$ grade, three $\mathrm{F}$ grades, and two $\mathrm{D}$ grades appeared. 


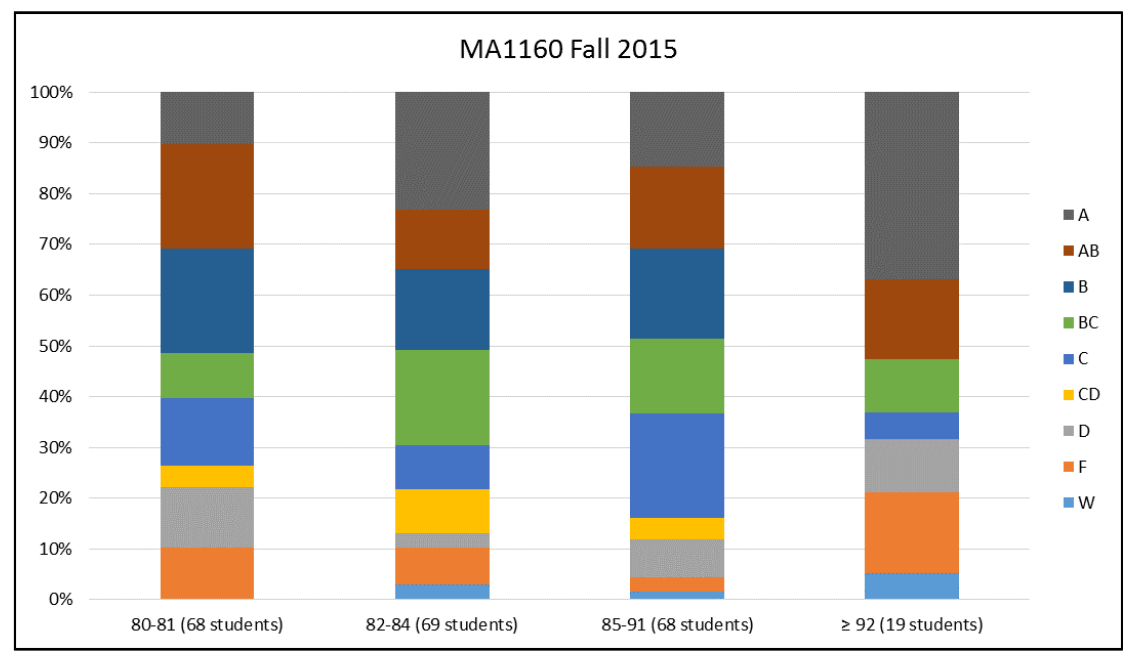

Figure 9. MA1160 final course grade distribution by placement test score range. 


\section{Chapter 6 - Influence of Path to Calculus I on Grades}

The second research question asked, "How do Calculus I course grades of the following groups compare to one another?"

- Students who achieved Calculus I placement on their first ALEKS placement test attempt

- Students who achieved Calculus I placement on their second or third ALEKS placement test attempt (after completing remediation exercises in ALEKS)

- Students who take Precalculus their first semester at MTU, and Calculus I the following semester

\section{Odds Ratios from Contingency Tables}

\section{Methodology}

Two approaches were used to explore the effects of various paths to Calculus I on grades in that course. For this investigation, no distinction was made between MA1161 and MA1160. Recall that these two courses cover the same content and use the same exams, but are taught at a different pace. Collectively, they are referred to as Calculus I in this analysis.

The first of these approaches began with constructing contingency tables for each of two midterm exams, a final exam, and the final course grade. The columns were labelled according to whether the score or grade was satisfactory or unsatisfactory. The rows were labelled to indicate the four paths to Calculus I defined below:

- Single ALEKS mathematics placement test attempt; enrolled in either MA1161 or MA1160 in Fall 2015

- Two or three ALEKS mathematics placement test attempts; jump type from lowest to 
highest placement was B, D, E, or F (lowest score qualified student for college algebra or MA1032; highest score qualified student for either MA1161 or MA1160); enrolled in either MA1161 or MA1160 in Fall 2015

- Two or three ALEKS mathematics placement test attempts; jump type from lowest to highest placement was $\mathrm{C}$ or $\mathrm{N}^{2}$ (all placement test attempts qualified student for either MA1161 or MA1160); enrolled in either MA1161 or MA1160 in Fall 2015

- Enrolled in MA1032 in Fall 2015 and MA1161 in Spring 2016

For the data in each contingency table, a chi-square test of independence was used to determine whether an observed difference in success rates among paths was statistically significant at the .05 level. The null hypothesis was that no difference in the probability of a satisfactory performance existed among the paths. The alternative hypothesis was that a difference did exist between at least two of the paths.

If the chi-square test indicated that a statistically significant difference existed among paths, odds ratios were used to estimate the factor by which a satisfactory performance was more likely. The odds ratio is a measure of association for 2 by 2 contingency tables. The odds of an event occurring is defined as the ratio of favorable outcomes to unfavorable outcomes. The odds ratio is simply the ratio of the odds of the same event occurring for two different groups. The further the odds ratio is from the baseline value of 1.0, the stronger the association (Agresti, 2007).

${ }^{2}$ Jump type A does not appear among the paths listed above because those students' highest placement test score did not qualify them for either MA1161 or MA1160. 


\section{Results}

Table 5 is the contingency table for Midterm Exam 1 in Calculus I. Scores of $70 \%$ or higher were considered satisfactory. Nonzero scores less than 70\% were considered unsatisfactory. Contingency tables for the second midterm exam, final exam, and final grade follow the same structure. For brevity, they appear in the Appendix.

\section{Table 5}

Contingency Table for Calculus I Midterm Exam 1 Scores

\begin{tabular}{lccc}
\hline Group & Satisfactory & Unsatisfactory & Total \\
\hline 1: Calculus I in Fall 2015, 1 ALEKS test attempt & 189 & 75 & 264 \\
$\begin{array}{l}\text { 2: Calculus I in Fall 2015, 2 or 3 ALEKS test attempts, } \\
\text { retake necessary for Calculus I placement }\end{array}$ & 113 & 123 & 236 \\
$\begin{array}{l}\text { 3: Calculus I in Fall 2015, 2 or 3 ALEKS test attempts, } \\
\text { retake optional for Calculus I placement }\end{array}$ & 15 & 2 & 17 \\
$\begin{array}{l}\text { 4: Precalculus in Fall 2015, Calculus I in Spring 2016 } \\
\text { Total }\end{array}$ & 42 & 35 & 77 \\
\hline
\end{tabular}

Table 6 provides a summary of the chi-square test statistics and accompanying $p$ values for this analysis. These results indicated that at all four assessment points considered, at the .05 level there was a statistically significant difference in satisfactory performance probabilities between at least two of the four groups. 
Table 6

Chi-Square Independence Test Results from a Comparison of Paths to Calculus I

\begin{tabular}{ccccc}
\hline & Midterm Exam 1 & Midterm Exam 2 & Final Exam & Final Grade \\
\hline$\chi^{2}$ & 35.908 & 74.409 & 34.220 & 56.814 \\
$p$ & $<.001$ & $<.001$ & $<.001$ & $<.001$ \\
\hline
\end{tabular}

In order to quantify the differences in probabilities between groups, odds ratios were calculated. Table 7 summarizes these results. The most interesting results are those in which all odds ratios within a row are statistically significant and consistently either less than or greater than the baseline value of 1.0. For example, consider the Groups 1 and 2 comparison in Table 7. These results indicate that at all three testing points within the Calculus I course, students who took the ALEKS placement test exactly once were at least 2.3 times more likely than those who required multiple attempts to receive a satisfactory exam score. This trend is obviously reflected in the final course grade. Group 4 is significantly different from all three other groups.

Comparing Groups 1 and 4, students who took the ALEKS placement test exactly once were at least 2.1 times more likely than those who started in Precalculus at MTU to receive satisfactory exam scores, with final grades coinciding. The Groups 3 and 4 comparison shows that students for whom the placement test retake was optional for Calculus I eligibility were 10.6 times more likely than those who started in Precalculus at MTU to receive a Calculus I final grade of C or better, this outcome the result of significant differences in exam performance. Group 2 was the least different from Group 4, with significant findings observed only in Midterm Exam 2 and final course grade performance. Necessary placement test retakers were 3.2 times more likely than students who started in Precalclus at MTU to receive a satisfactory Midterm Exam 2 score, 
and 2.0 times more likely to receive a final grade of $\mathrm{C}$ or better. Groups 2 and 3 were distinguishable by their performance on the first midterm exam, where optional retakers were 8.2 times more likely than necessary retakers to receive a satisfactory score, and the final exam, where the same group was 4.5 times more likely to receive a satisfactory score. Groups 1 and 3 were not distinguishable at any testing point nor at the final grade mark. Considering one column at a time, the results in Table 7 suggest that the second midterm exam was the largest differentiator between groups. Groups 1, 2, and 3 were more likely than Group 4 to receive a score of $70 \%$ or better on this exam by factors of 9.5, 3.2, and 14.0 respectively. Group 1 was 3.0 times more likely than Group 2 to perform satisfactorily.

Table 7

Odds Ratios, Success Defined as Satisfactory Score or Grade

\begin{tabular}{ccccc}
\hline $\begin{array}{c}\text { Groups } \\
\text { Compared }\end{array}$ & $\begin{array}{c}\text { Calculus I } \\
\text { Midterm Exam } \\
\text { 1 Odds Ratio }\end{array}$ & $\begin{array}{c}\text { Calculus I } \\
\text { Midterm Exam } \\
\text { 2 Odds Ratio }\end{array}$ & $\begin{array}{c}\text { Calculus I } \\
\text { Final Exam } \\
\text { Odds Ratio }\end{array}$ & $\begin{array}{c}\text { Calculus I } \\
\text { Final Grade } \\
\text { Odds Ratio }\end{array}$ \\
\hline 1 and 2 & $2.743^{* * *}$ & $2.969^{* * *}$ & $2.317^{* * *}$ & $2.980^{* * *}$ \\
1 and 3 & 0.336 & 0.677 & 0.512 & 0.563 \\
1 and 4 & $2.100^{*}$ & $9.484^{* * *}$ & $3.756^{* * *}$ & $5.964^{* * *}$ \\
2 and 3 & $0.122^{* *}$ & 0.228 & $0.221^{*}$ & 0.189 \\
2 and 4 & 0.766 & $3.194^{* * *}$ & 1.621 & $2.001^{*}$ \\
3 and 4 & 6.250 & $14.000^{* * *}$ & $7.333^{* *}$ & $10.588^{* *}$ \\
\hline
\end{tabular}

Note. Group 1: Calculus I in Fall 2015, 1 ALEKS test attempt

Group 2: Calculus I in Fall 2015, 2 or 3 ALEKS test attempts, retake necessary for Calculus I placement

Group 3: Calculus I in Fall 2015, 2 or 3 ALEKS test attempts, retake optional for Calculus I placement

Group 4: Precalculus in Fall 2015, Calculus I in Spring 2016

$* * * p<.001 . * * p<.01 . * p<.05$. Bonferroni correction applied. 


\section{Logistic Regression Applied to Retaker Data}

\section{Methodology}

The results of the analysis just described prompted a follow on investigation referred to as the retaker analysis. The new questions under study were whether students who achieved an initial placement in College Algebra, and a final placement in MA1161 or MA1160 achieved significantly different course outcomes compared to students who achieved an initial placement in MA1032, and a final placement in MA1161 or MA1160. Furthermore, was there a significant difference between students who used exactly two placement test attempts versus three?

In the first of two rounds of the retaker analysis, the coded final exam performance (satisfactory or unsatisfactory) was defined as the response in a logistic regression model. In the second round, the coded final course grade (satisfactory or unsatisfactory) was defined as the response. The predictors in each round were the jump type (college algebra initial placement to calculus final placement, signified by jump type D or F, or MA1032 initial placement to calculus final placement, signified by jump type B or E) and number of placement tests taken (2 or 3).

A check for correlation between the two predictors gave an approximate linear correlation coefficient of 0.3 in both rounds. This correlation was not deemed strong enough to preclude trying to fit a model that included both jump type and number of placement test attempts as predictors.

The statistical software package $\mathrm{R}$ was used to find coefficients $\alpha, \beta_{1}$, and $\beta_{2}$ for the following model in each round (R Core Team, 2016):

$$
\operatorname{logit}[P(Y=1)]=\alpha+\beta_{1} x_{1}+\beta_{2} x_{2}
$$


where

$Y=$ whether a satisfactory score or grade was achieved $(1=$ yes, $0=$ no $)$,

$x_{1}=0$ if jump type was $\mathrm{D}$ or $\mathrm{F}$ (initial placement college algebra, highest placement calculus),

$x_{1}=1$ if jump type was B or E (initial placement precalculus, highest placement calculus),

$x_{2}=2$ if exactly 2 tests taken,

$x_{2}=3$ if exactly 3 tests taken.

After estimating coefficients for the above model, a series of likelihood ratio tests were performed to assess the model fit. A likelihood ratio test is a test for two nested models that incorporates the maximized log-likelihood, $L$, for each model. The test indicates if the small model's fit is significantly worse than the full model's fit. If the full model has $f$ variables and the small model has $s$ variables, then the test value is compared against a chi-square distribution with $f-s$ degrees of freedom:

$$
-2\left(L_{\text {small model }}-L_{\text {full model }}\right) \sim \chi_{f-s}^{2}
$$

First, the null hypothesis $H_{0}$ was taken to be $\beta_{1}=\beta_{2}=0$ and the alternative hypothesis $H_{a}$ was $\beta_{1} \neq 0$ or $\beta_{2} \neq 0$. This choice of hypotheses tests whether either of the predictors have any statistically significant correlation with the response. The full model was therefore

$$
\operatorname{logit}[P(Y=1)]=\alpha+\beta_{1} x_{1}+\beta_{2} x_{2}
$$

This was compared with a reduced model that contained only an intercept term:

$$
\operatorname{logit}[P(Y=1)]=\alpha
$$

In both rounds, the result of the likelihood ratio test was found to be significant at the .05 level, 
thus $H_{0}$ was rejected and tests were performed on the individual regression parameters.

In each round, the null hypothesis was first revised to be $H_{0}: \beta_{1}=0$. The reason for doing this was to test whether jump type had a significant effect on the response (final exam score or final course grade, depending on the round). The alternative hypothesis became $H_{a}: \beta_{1} \neq 0$. The full model was then

$$
\operatorname{logit}[P(Y=1)]=\alpha+\beta_{1} x_{1}+\beta_{2} x_{2}
$$

The new reduced model was

$$
\operatorname{logit}[P(Y=1)]=\alpha+\beta_{2} x_{2}
$$

A likelihood ratio test was then performed to test for significance.

Finally, to test whether the number of placement test attempts had a significant effect on the response (final exam score or final course grade, depending on the round), the null hypothesis was revised to be $H_{0}: \beta_{2}=0$ and compared to an alternative hypothesis of $H_{a}: \beta_{2} \neq$ 0. The full model was then

$$
\operatorname{logit}[P(Y=1)]=\alpha+\beta_{1} x_{1}+\beta_{2} x_{2}
$$

The revised reduced model was

$$
\operatorname{logit}[P(Y=1)]=\alpha+\beta_{1} x_{1}
$$

A likelihood ratio test was performed to test for significance.

In each round, the results of the significance tests performed above were used to select the best model structure from those considered. R was then used to recalculate coefficients. Finally, coefficients were interpreted as odds ratios. 


\section{Results}

Applying logistic regression to the final exam score dataset $(n=215)$ produced the following result:

$$
\operatorname{logit}[P(Y=1)]=-1.4601+1.5032 x_{1}-0.1975 x_{2}
$$

The series of likelihood ratio tests described in the methodology were then performed to assess the overall model fit. First, the null hypothesis $H_{0}$ was taken to be $\beta_{1}=\beta_{2}=0$ and the alternative hypothesis $H_{a}$ was $\beta_{1} \neq 0$ or $\beta_{2} \neq 0$. This comparison produced a chi-square test statistic of 21.781, which, when compared to a chi-square distribution with two degrees of freedom, indicated $p<.001$. At the .05 level, evidence existed to support rejecting the null hypothesis. The full model provided a better fit to the data than the reduced model with only an intercept term.

Next, significance tests were performed on the individual regression parameters. The new null hypothesis was taken to be $H_{0}: \beta_{1}=0$, and the new alternative hypothesis was $H_{a}: \beta_{1} \neq 0$. This comparison produced a chi-square test statistic of 18.751, which, when compared to a chisquare distribution with one degree of freedom, indicated $p<.001$. At the .05 level, jump type had a significant impact on the probability of earning a Calculus I final exam score of $70 \%$ or better, once the number of assessments taken was included in the model.

The null and alternative hypotheses were revised once again $\left(H_{0}: \beta_{2}=0, H_{a}: \beta_{2} \neq 0\right)$. This comparison produced a chi-square test statistic of 0.149 , which, when compared to a chisquare distribution with one degree of freedom, indicated $p=.699$. At the .05 level, the number of placement tests taken did not have a significant impact on the probability of earning a 
Calculus I final exam score of $70 \%$ or better, once jump type was included in the model.

In light of the above results, the best fitting model among those tested was

$$
\operatorname{logit}[P(Y=1)]=\alpha+\beta_{1} x_{1}
$$

Coefficients $\alpha$ and $\beta_{1}$ were recalculated, producing the following result:

$$
\operatorname{logit}[P(Y=1)]=-1.9095+1.5449 x_{1}
$$

To estimate how the odds of receiving a Calculus I final exam score of $70 \%$ or better change as a function of jump type, $e^{\beta_{1}}$ was computed, giving $e^{1.5449} \approx 4.7$. Independent of whether the placement test was taken twice or three times, the estimated odds of receiving a Calculus I final exam score of $70 \%$ or better are 4.7 times greater for those students who initially placed into Precalculus rather than College Algebra, but placed into Calculus I with a later testing attempt.

For the second round of analysis, the response was changed to the student's final grade in Calculus I. Applying logistic regression to the final grade dataset $(n=220)$ produced the following result:

$$
\operatorname{logit}[P(Y=1)]=0.6004+1.1493 x_{1}-0.3999 x_{2}
$$

Following the approach of the first round, a series of likelihood ratio tests were performed to assess the overall model fit. First, the null hypothesis $H_{0}$ was taken to be $\beta_{1}=$ $\beta_{2}=0$ and the alternative hypothesis $H_{a}$ was $\beta_{1} \neq 0$ or $\beta_{2} \neq 0$. This comparison produced a chi-square test statistic of 20.358, which, when compared to a chi-square distribution with two degrees of freedom, indicated $p<.001$. At the .05 level, evidence existed to support rejecting 
the null hypothesis. The full model provided a better fit to the data than the reduced model with only an intercept term.

Next significance tests were performed on the individual regression parameters. The new null hypothesis was taken to be $H_{0}: \beta_{1}=0$, and the new alternative hypothesis was $H_{a}: \beta_{1} \neq 0$. This comparison produced a chi-square test statistic of 15.325 , which, when compared to a chisquare distribution with one degree of freedom, indicated $p<.001$. At the .05 level, jump type had significant impact on the probability of earning a Calculus I final grade of $\mathrm{C}$ or better, once number of assessments taken was included in the model.

The null and alternative hypotheses were revised once again $\left(H_{0}: \beta_{2}=0, H_{a}: \beta_{2} \neq 0\right)$. This comparison produced a chi-square test statistic of 1.023 , which, when compared to a chisquare distribution with one degree of freedom, indicated $p=.312$. At the .05 level, the number of placement tests taken did not have a significant impact on the probability of earning a Calculus I final grade of $\mathrm{C}$ or better, once jump type was included in the model.

In light of the above results, the best fitting model among those tested was

$$
\operatorname{logit}[P(Y=1)]=\alpha+\beta_{1} x_{1}
$$

Coefficients $\alpha$ and $\beta_{1}$ were recalculated, producing the following result:

$$
\operatorname{logit}[P(Y=1)]=-0.3118+1.2338 x_{1}
$$

To estimate how the odds of receiving a Calculus I final grade of $\mathrm{C}$ or better change as a function of jump type, $e^{\beta_{1}}$ was computed, giving $e^{1.2338} \approx 3.4$. Independent of whether the placement test was taken twice or three times, the estimated odds of receiving a Calculus I final 
grade of $\mathrm{C}$ or better were 3.4 times greater for those students who initially placed into Precalculus rather than College Algebra, but achieved Calculus I placement with a later testing attempt. 


\section{Chapter 7 - ALEKS Subscore Influence on Calculus I Performance}

The third research question asked, "Does a lack of incoming proficiency in any particular curriculum area for which the ALEKS placement test provides a subscore correlate with a decreased likelihood of successful course performance?

\section{Subscore Summaries by Course}

\section{Methodology}

A preliminary analysis of the ALEKS subscore data was undertaken to reveal which curriculum areas, if any, might differentiate successful Precalculus and Calculus I students from unsuccessful ones. One box and whisker plot was constructed from the subscores of students who enrolled in MA1032 in Fall 2015; a second utilized the subscores of students who enrolled in either MA1161 or MA1160 in Fall 2015.

\section{Results}

Figure 10 shows the subscore quartile and range summary for the students who enrolled in MA1032 in Fall 2015. The whole numbers, fractions, and decimals five number summary appears incomplete because the quartiles and the maximum were all $100 \%$. The curriculum areas having the lowest medians were exponentials and logarithms (median subscore 20\%) and trigonometry (median subscore 15.5\%). 


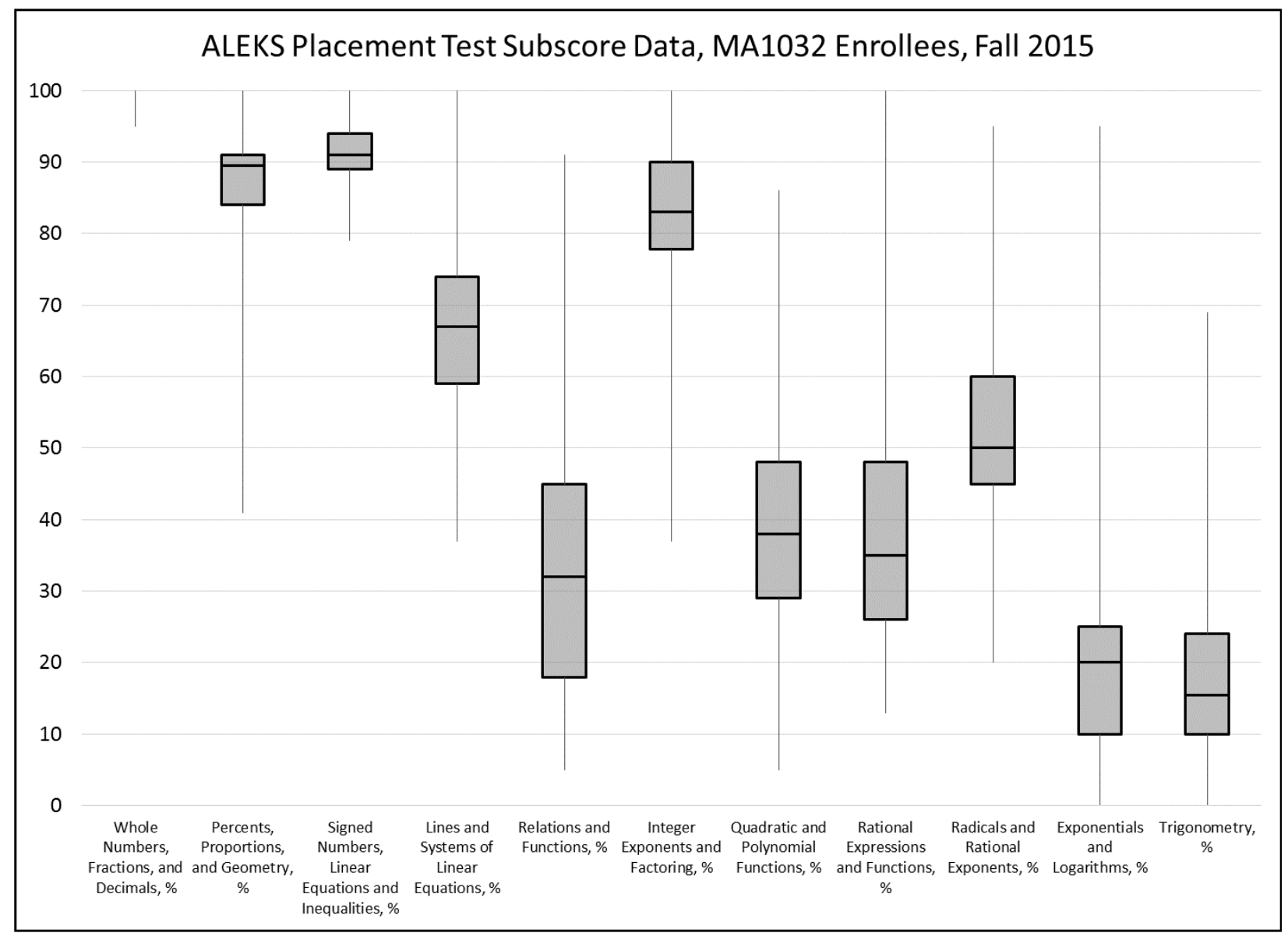

Figure 10. Placement test subscore quartiles and ranges, Fall 2015 MA1032 students.

Figure 11 shows the results of a similar analysis conducted using subscore data from students who took either MA1161 or MA1160 in Fall 2015. As was the case for MA1032, the whole numbers, fractions, and decimals five number summary appears incomplete because the quartiles and the maximum were all 100\%. The compressed box for the percents, proportions, and geometry subscore reflects all three quartiles being 97\%. Once again, the curriculum areas having the lowest medians were exponentials and logarithms and trigonometry (both medians were $45 \%$ ). 


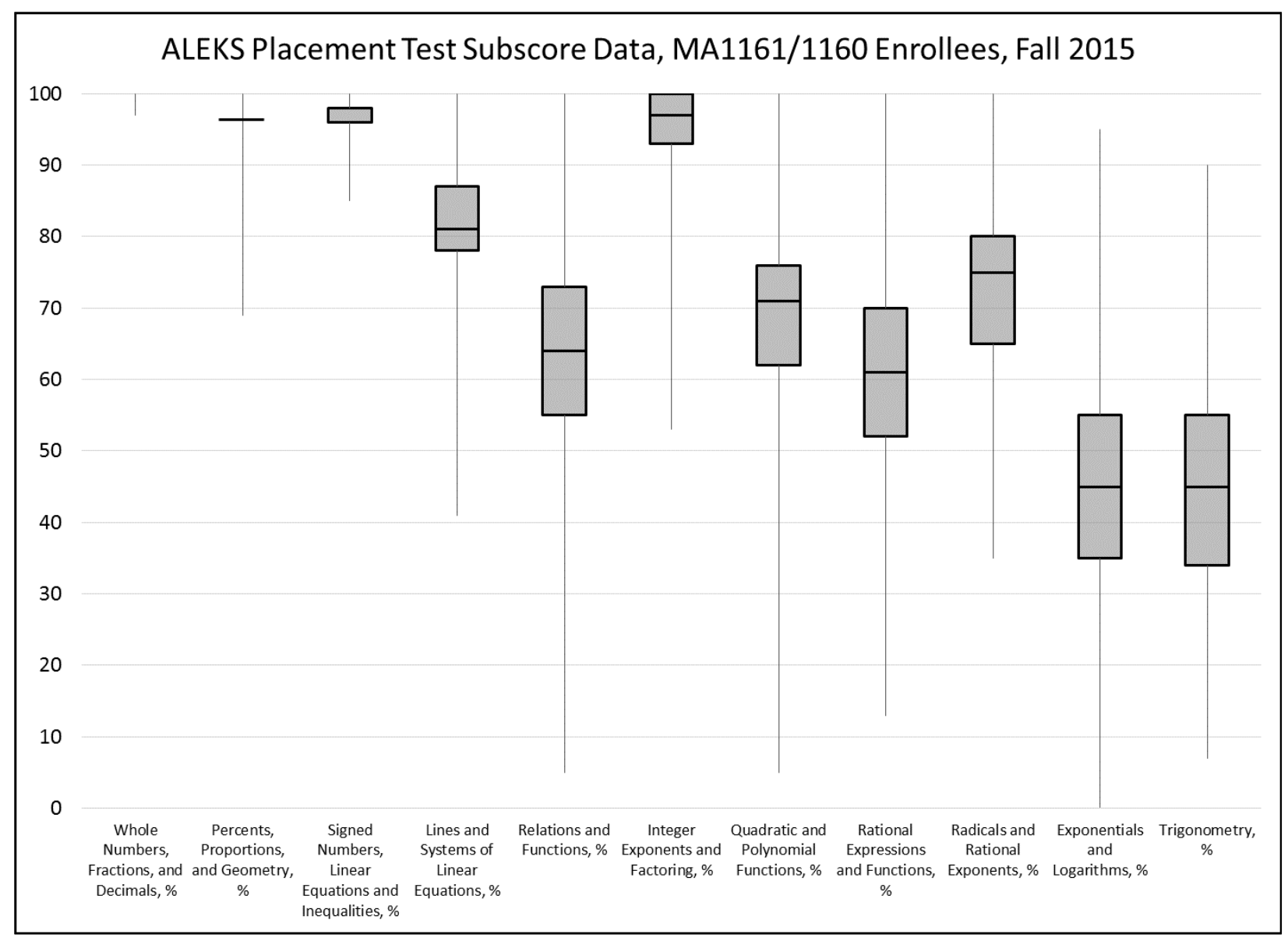

Figure 11. Placement test subscore quartiles and ranges, Fall 2015 MA1161/1160 students.

\section{Logistic Regression Using Subscore Data}

\section{Methodology}

It was not particularly concerning that the MA1032 cohort showed a significant weakness in their facility with exponentials and logarithms, and trigonometry, since these are all topics that are covered at length in MA1032. What was concerning is these same curriculum areas were commonly the weakest part of background for students who placed into MA1161 or MA1160, which will again be collectively referred to as Calculus I. This observation prompted a logistic regression analysis nearly identical to the retaker analysis used to investigate Research Question

2. Consequently, less detail will be provided here. The focus of the analysis was restricted to 
students who took MA1161 or MA1160 in Fall 2015. In the first of two rounds of this analysis, the coded final exam performance (satisfactory or unsatisfactory) was defined as the response in a logistic regression model, with the exponentials and logarithms subscore and the trigonometry subscore appearing as predictors. In the second round of analysis, the coded final course grade (satisfactory or unsatisfactory) was the response, with the same predictors as the first round.

Before proceeding with the analysis in each round, a simple scatter plot was produced showing exponentials and logarithms subscore versus trigonometry subscore. A linear correlation coefficient was then calculated, giving a result of approximately 0.6 in both rounds. It was decided that this correlation was not strong enough to prohibit attempting to fit a model that included both subscores as predictors.

The statistical software package $\mathrm{R}$ was used to find coefficients $\alpha, \beta_{1}$, and $\beta_{2}$ for the following model:

$$
\operatorname{logit}[P(Y=1)]=\alpha+\beta_{1} x_{1}+\beta_{2} x_{2}
$$

where

$Y=$ whether a satisfactory score or grade was achieved $(1=$ yes, $0=$ no $)$,

$x_{1}=$ Exponentials and Logarithms ALEKS Placement Test Subscore (\%),

$x_{2}=$ Trigonometry ALEKS Placement Test Subscore (\%).

The same series of likelihood tests that were used in pursuit of an answer to Research Question 2 were used here to compare the fit of the above full model to reduced versions of the model. The results of these tests were then used to select the best model structure from those considered. R was used to recalculate coefficients, which were then interpreted as odds ratios. 


\section{Results}

Applying logistic regression to the final exam score dataset $(n=491)$ produced the following result:

$$
\operatorname{logit}[P(Y=1)]=-1.4266-0.0093 x_{1}+0.0324 x_{2}
$$

A series of likelihood ratio tests were then performed to assess the overall model fit.

First, the null hypothesis $H_{0}$ was taken to be $\beta_{1}=\beta_{2}=0$ and the alternative hypothesis $H_{a}$ was $\beta_{1} \neq 0$ or $\beta_{2} \neq 0$. This comparison produced a chi-square test statistic of 22.284 , which, when compared to a chi-square distribution with two degrees of freedom, indicated $p<.001$. At the .05 level, evidence existed to support rejecting the null hypothesis. The full model provided a better fit to the data than the reduced model with only an intercept term.

Next significance tests were performed on the individual regression parameters. The new null hypothesis was taken to be $H_{0}: \beta_{1}=0$, and the new alternative hypothesis was $H_{a}: \beta_{1} \neq 0$. This comparison produced a chi-square test statistic of 1.761, which, when compared to a chisquare distribution with one degree of freedom, indicated $p=.184$. At the .05 level, the exponentials and logarithms subscore did not have a significant impact on the probability of earning a Calculus I final exam score of $70 \%$ or better, once the trigonometry subscore was included in the model.

The null and alternative hypotheses were revised once again $\left(H_{0}: \beta_{2}=0, H_{a}: \beta_{2} \neq 0\right)$. This comparison produced a chi-square test statistic of 19.295 , which, when compared to a chisquare distribution with one degree of freedom, indicated $p<.001$. At the .05 level, the trigonometry subscore had a significant impact on the probability of earning a Calculus I final 
exam score of $70 \%$ or better, once the exponentials and logarithms subscore was included in the model.

In light of the above results, the best fitting model among those tested was

$$
\operatorname{logit}[P(Y=1)]=\alpha+\beta_{2} x_{2}
$$

Coefficients $\alpha$ and $\beta_{2}$ were recalculated, producing the following result:

$$
\operatorname{logit}[P(Y=1)]=-1.5772+0.0264 x_{2}
$$

To estimate how the odds of receiving a Calculus I final exam score of $70 \%$ or better change as a function of trigonometry subscore, $e^{\beta_{2}}$ was calculated, giving $e^{0.0264} \approx 1.03$. This indicates that a $1 \%$ increase in trigonometry subscore is expected to increase the odds of earning a Calculus I final exam score of $70 \%$ or better by $3 \%$.

For the second round of analysis, the response was changed to the student's final grade in Calculus I. Applying logistic regression to the final course grade dataset $(n=497)$ produced the following result:

$$
\operatorname{logit}[P(Y=1)]=-0.3939+0.0001 x_{1}+0.0299 x_{2}
$$

As before, a series of likelihood ratio tests were performed to assess the overall model fit. First, the null hypothesis $H_{0}$ was taken to be $\beta_{1}=\beta_{2}=0$ and the alternative hypothesis $H_{a}$ was $\beta_{1} \neq 0$ or $\beta_{2} \neq 0$. This comparison produced a chi-square test statistic of 21.587 , which, when compared to a chi-square distribution with two degrees of freedom, indicated $p<.001$. At the .05 level, evidence existed to support rejecting the null hypothesis. The full model fit the data better than the reduced model with only an intercept term. 
Significance tests were then performed on the individual regression parameters. The new null hypothesis was taken to be $H_{0}: \beta_{1}=0$, and the new alternative hypothesis was $H_{a}: \beta_{1} \neq 0$. This comparison produced a chi-square test statistic of 0.0003 , which, when compared to a chisquare distribution with one degree of freedom, indicated $p=.986$. At the .05 level, the exponentials and logarithms subscore did not have a significant impact on the probability of earning a Calculus I final grade of $\mathrm{C}$ or better, once the trigonometry subscore was included in the model.

The null and alternative hypotheses were revised once again $\left(H_{0}: \beta_{2}=0, H_{a}: \beta_{2} \neq 0\right)$. This comparison produced a chi-square test statistic of 14.007, which, when compared to a chisquare distribution with one degree of freedom, indicated $p<.001$. At the .05 level, the trigonometry subscore had a significant impact on the probability of earning a Calculus I final grade of $\mathrm{C}$ or better, once the exponentials and logarithms subscore was included in the model.

In light of the above results, the best fitting model among those tested was

$$
\operatorname{logit}[P(Y=1)]=\alpha+\beta_{2} x_{2}
$$

Coefficients $\alpha$ and $\beta_{2}$ were recalculated, producing the following result:

$$
\operatorname{logit}[P(Y=1)]=-0.3915+0.0299 x_{2}
$$

To estimate how the odds of receiving a Calculus I final grade of $\mathrm{C}$ or better change as a function of trigonometry subscore, $e^{\beta_{2}}$ was calculated, giving $e^{0.0299} \approx 1.03$. This indicates that for a fixed exponentials and logarithms subscore, a $1 \%$ increase in trigonometry subscore is expected to increase the odds of earning a Calculus I final grade of C or better by $3 \%$. 


\section{Chapter 8 - Discussion, Conclusions and Recommendations}

\section{Research Question 1: Cut Score Influence on Pass Rates}

The first research question asked whether the ALEKS cut scores being used to determine MA1032, MA1161, and MA1160 placement result in the expected pass rates for those courses. The results presented in Chapter 5 provide data on which to base that decision.

For all three courses, the probability of earning a final grade of $\mathrm{C}$ or better generally increased with an increasing placement test score. In a related manner, the probability of earning a CD or lower generally decreased with increasing placement test score. This is consistent with the observations made at the University of Illinois (Reddy \& Harper, 2013b).

Given a placement test score at or above the MA0132 cut score of 56, the probability of receiving a $\mathrm{C}$ or better in that course was at least 0.72 . This seems to be a reasonable chance of success, indicating that the cut score is not too low. Insufficient data exist to determine whether the cut score is higher than necessary to achieve an acceptable likelihood of success for a student enrolling in MA1032.

In MA1161, given a placement test score at or above the cut score of 70 , the probability of receiving a $\mathrm{C}$ or better was at least 0.64 . This probability increased to 0.69 given a placement test score of 73 or better. The reason for highlighting this particular pivot will become clear after the DFW rates are reviewed in a later paragraph.

Finally, given a placement test score at or above the MA1160 cut score of 80 , the probability of receiving a $\mathrm{C}$ or better in that course was at least 0.79 . Certainly overplacement is not an issue here. Insufficient data exist to conclude how students who achieved lower placement test scores, say in the 75-79 range, might perform in MA1160. While the MA1161 probabilities 
at pivots in this range hint at a high likelihood of success, one must keep in mind that MA1161 offers students a slower pace and more contact time with their instructor.

A more common metric for determining whether students are passing courses in acceptable numbers is the DFW rate. The second analysis presented in Chapter 5 produced these rates for MA1032, MA1161, and MA1160 overall, as well as by ALEKS placement test score range. While no actual targets exist, Michigan Technological University Mathematical Sciences Department Chair Dr. Mark Gockenbach suggested that for MA1032, an overall DFW rate below $20 \%$ would be considered very good (personal communication, October 11, 2016). For MA1160, he commented that an overall DFW rate greater than $20 \%$ would be disappointing. Since MA1161 admits students with lower placement test scores than those required for MA1160, the overall DFW rate might be higher among that population.

The results of this study showed that an acceptable overall DFW rate for a course may mask significantly higher rates among subgroups identifiable by placement test score range. For example, the overall DFW rate among students taking MA1032 Fall 2015 was 18\%, but among students with placement test scores in the 56-60 range (56 is the cut score) it was $25 \%$. Nine of the forty students in this group received failing final grades (none withdrew). Given the small numbers involved, it might be wise to review individual records to determine why these students failed the course before concluding that the cut score for this course is too low. The reason may be related to absenteeism, or some other factor wholly within the student's control. Also, data from later semesters should be examined to increase the sample size.

The overall DFW rate among students taking MA1161 in Fall 2015 was 31\%. The subgroup of students with placement test scores between the cut score of 70 and 72 had the 
highest DFW rate for this course at $41 \%$. Eighteen of the seventy students with scores in this range failed the course and four withdrew. Once again, given the relatively small numbers of students involved, it might be wise to review individual records to try to determine whether these students were overplaced given their mathematical background, or whether extenuating circumstances were to blame for their performance. If a larger sample size indicates overplacement, increasing the cut score for MA1161 to 73 should be considered. The observed DFW rate for MA1161 students with placement test scores in the 73-75 range was 30\%, which, if reproduced with a larger sample, would be a vast improvement for the population with placement test scores at or barely above the cut score. The only subgroup with a DFW rate below $20 \%$ was that consisting of students with placement test scores of 80 and above (which qualified them for MA1160). At the upper end of the placement test score range for which a student would be placed in MA1161 (78-79), the DFW rate was still 26\%, so underplacement should not be a concern when using 79 as an upper bound.

The cut score for MA1160 is 80 . The DFW rate in this course for students with placement test scores of $80-81$ was $22 \%$, five points above the overall MA1160 DFW rate of $17 \%$. Overplacement does not seem to be a substantial issue with a cut score of 80 . Ranges capturing scores between 82 and 91, inclusive, had DFW rates below 15\%. While this may suggest underplacement, remember that the ALEKS PPL product is not designed to assess Calculus II readiness. Among students with placement test scores of 92 or higher, the DFW rate was a surprise at $32 \%$, but this result could be attributed to the small sample size of only 19 students.

Looking across all three of the courses studied, in general, DFW proportions decreased 
with increasing placement test scores. This aligns with what was observed at the University of Illinois (Reddy \& Harper, 2013b).

In summary, the cut scores currently in place for MA1032 and MA1160 appear to support acceptable pass rates for those courses. With regard to MA1161, the results of this study suggest the cut score of 70 may be too low. If repeating the conditional probability and DFW rate analyses on a larger data set produces results consistent with those presented in this report, increasing the MA1161 cut score to 73 should be considered.

\section{Research Question 2: Influence of Path to Calculus I on Grades}

The second research question asked whether a student's path to Calculus I significantly influenced their likelihood of being successful in that course. The paths compared in Chapter 6 were a single placement test attempt, necessary repeated placement test attempts, optional repeated placement test attempts, and starting in Precalculus at MTU. Between attempts, students were required to complete at least three hours of work in the ALEKS Prep and Learning Module.

Looking across the results of the three exams given in Calculus I in Fall 2015, it was found that students who placed into the course after a single test attempt were always at least 2.3 times more likely to achieve an exam score of $70 \%$ or higher than students for whom a placement test retake was necessary. At the final grade mark, the odds ratio indicated these same students were three times more likely to receive a $\mathrm{C}$ or better in the course. This result is consistent with what Adaricheva and Assylbekov (2013) observed at Nazarbayev University. They found that learning gains suggested by retake scores being higher than initial scores are short lived, since if students tested a third time three months after the second attempt, their scores reverted back to essentially their initial scores. Recall that the placement testing portal at MTU 
was open from May 1 through June 30, 2015, and classes began August 31. Thus there was a lag of at least two and up to four months between the time a student received the placement test score that secured them a seat in Calculus I and the beginning of the course. The results of the current study support a conclusion that completing remediation exercises inside ALEKS will likely help a student achieve a higher placement test score, but that retraining may not be sufficient to strengthen their background to the point where they are indistinguishable from a student who only required one attempt to place into Calculus I.

Again looking across the three exams, students who placed into Calculus I after a single test attempt were at least 2.1 times more likely to achieve an exam score of $70 \%$ or higher than students who started in Precalculus at MTU. When final grades were compared, students in the single attempt group were six times more likely to receive a $\mathrm{C}$ or better in the course.

Comparing the group of students for whom the placement test retake was optional with those who started in Precalculus, the results were not surprising. The optional retakers were 10.6 times more likely to receive a final grade of $\mathrm{C}$ or better, and this difference was driven by significant differences in exam performance.

Unfortunately, this situation that students who begin their college mathematics courses in Precalculus struggle to be successful in Calculus I is apparently widespread. Sonnet and Sadler (2014) saw no statistically significant indication that taking a college pre-calculus course helped students' later performance in college calculus. Their work was based on a US sample of 5507 students at 132 institutions. They did not offer a definitive reason why this is the case, nor did they offer a certain remedy.

One other interesting finding from this particular odds ratio analysis was that among the 56 
three exams, the second exam was the greatest differentiator between groups. The single placement test attempt students were three times more likely than the necessary retakers to receive a score of $70 \%$ or better on that exam. Compared to the students that started in Precalculus at MTU, students who came to the Calculus I course from any of the other paths investigated were between 3.2 and 14 times more likely to receive a score of $70 \%$ or higher on the second exam. This is a curious result, suggesting a direction for future work. If an item analysis were done, one should look for a distinct difference in content between the Calculus I exams given in Fall 2015 and in Spring 2016. If the exams were similar, the explanation may be that the Precalculus curriculum prepares students best for the topics covered early in Calculus I, but does little to set the stage for later topics.

The second analysis presented in Chapter 6 aimed to investigate further the necessary retakers, that is the group of students who needed more than one placement test attempt to qualify for MA1160 or MA1161. The preliminary score earned by some of those students suggested College Algebra was an appropriate first course for them, whereas higher initial scores indicated readiness for Precalculus. The logistic regression results showed that the estimated odds of receiving a satisfactory MA1161/1160 final exam score were 4.7 times greater for those students who initially placed into Precalculus rather than College Algebra. When final course grade was considered, the estimated odds of a satisfactory result were 3.4 times greater for the same group. The number of times the placement test was taken, 2 versus 3 , was not found to be significant.

Combined with the conclusion drawn from the previous analysis, this result highlights a path to Calculus I that is very unlikely to have a satisfactory outcome: a sequence of placement 
test attempts that initially indicate only College Algebra readiness but ultimately indicate Calculus I readiness. It may be wise to add a rule to the first year mathematics placement policy that accepts only one course level improvement resulting from all testing attempts.

\section{Research Question 3: ALEKS Subscore Influence on Calculus I Performance}

The final research question asked whether a lack of incoming proficiency in any particular curriculum area for which ALEKS subscores are available correlated with a decreased likelihood of successful course performance. The two areas having the lowest medians among both the MA1032 and MA1161/60 populations were exponentials and logarithms, and trigonometry (although the medians in these areas more than doubled from MA1032 to MA1161/1160). A considerable amount of time is spent on these subjects in MA1032, so the results were not especially troubling for that course. Among MA1161/1160 students, these subscore medians were the only two among the eleven that were less than $50 \%$. The fact that students who achieved an overall score sufficient for Calculus I placement routinely exhibited a lack of proficiency in these two curriculum areas prompted the logistic regression analysis presented in Chapter 7. That analysis revealed that a $1 \%$ increase in trigonometry subscore increased the odds of earning a satisfactory MA1161/1160 final exam score by 3\%, with an identical improvement in the odds of receiving a satisfactory final grade. The exponentials and logarithms subscore did not have a significant effect on either performance measure.

In response to the research question, a deficient background in trigonometry, as measured by the ALEKS PPL product, did correlate with a reduced likelihood of success on the Fall 2015 final exam given in Calculus I. The same correlation was observed in the final course grade data. Interestingly, while the final exam given that semester contained five questions involving 
trigonometric functions, four of those questions required that a derivative be computed, and one required that an indefinite integral be evaluated (Michigan Technological University Mathematical Sciences Department, 2015). Considering all three exams, which would comprise the largest portion of the final grade, all but three questions involving trigonometric functions required computing the derivative of that function. The other three trigonometry questions required that students evaluate a limit, find a specific antiderivative given an initial condition, and evaluate an indefinite integral. The derivative questions would not have required a strong background in trigonometry as much as they would have relied on students knowing the rules for differentiating trigonometric functions. The trigonometry problem types in the ALEKS PPL product do not include differentiation or integration (ALEKS Corporation, 2016). Hence, while the correlation was found to be statistically significant, it may be that trigonometry proficiency demonstrated on the placement test is an indicator of another skill helpful in undergraduate mathematics, such as the ability to successfully memorize large numbers of formulas. Using a mutual information analysis, Reddy and Harper (2013a) also saw a high correlation between the trigonometry subscore and final grade distribution in Business Calculus at the University of Illinois. This was surprising because that course did not use trigonometry at all. They attributed the correlation to the mathematical maturity of students proficient in trigonometry.

\section{Conclusions and Recommendations}

To summarize, the cut scores currently in place produce acceptable probabilities of satisfactory outcomes and acceptable DFW rates for MA1160. In MA1032, the probability of success at the cut score is acceptable, but the DFW rate of students with placement test scores at this level exceeds an internal threshold of $20 \%$. In MA1161, the probability of a satisfactory 
outcome for a student who just made the cut score is the lowest of all three courses studied at 0.64. Also, the MA1161 DFW rate is $41 \%$ for students with placement test scores at or just slightly above the cut score. It would be wise to repeat these two analyses on a larger data set. If the results are similar, increasing the MA1161 cut score from 70 to 73 is recommended.

One of the main reasons for changing to the ALEKS placement test for mathematics was to allow students a retake opportunity. The results of this study show that students who place into Calculus I on their first testing attempt are the most likely to be successful in the course. In particular, students with preliminary placement test results indicating only College Algebra readiness are very unlikely to be successful in MA1161 or MA1160, despite a later placement testing attempt that meets or exceeds the cut score for that course. Recalling that between placement test attempts students are required to spend a minimum of three hours working in the ALEKS Prep and Learning Module, these results call into question the degree to which this form of self-remediation produces lasting learning gains.

Subscore data revealed that most students in the combined MA1161/MA1160 population exhibited knowledge gaps in trigonometry. This was true also of the MA1032 population, but is not as concerning because trigonometry comprises a large portion of that course's syllabus. Logistic regression showed that a $1 \%$ increase in trigonometry subscore increased the odds of earning a satisfactory MA1161/1160 final exam score by 3\%, with an identical improvement in the odds of receiving a satisfactory final grade. These correlations existed despite the fact that the trigonometric exam content was predominantly differentiation, which relies more on mastering a set of rules taught in Calculus I than applying prior knowledge of trigonometry. No action in response to this data is recommended. 


\section{Directions for Future Research}

Three additional recommendations are provided that do not tie directly to any of the research questions. First, while MA1161 and MA1160 use common exams, the courses are different in pace and in the minimum placement test score necessary for enrollment. It might be informative to repeat the analyses described in Chapters 6 and 7 with the information from each course tabulated separately.

Second, Fall 2015 was the first semester that MA1161 and MA1160 sections used a newly adopted calculus text. A precalculus text by the same author is being considered for MA1032. If that text is adopted, it would be interesting to see if the performance gap between students who start their MTU mathematics sequence in MA1032 and those who start in MA1161 or MA1160 gets smaller.

Finally, purchasing the ALEKS PPL product gives students twelve months of access and five placement test attempts (ALEKS Corporation, n.d.-b). Since MTU restricts the number of placement test attempts to three, it may be possible to use one or both of the remaining attempts to reevaluate readiness for MA1161 or MA1160 after completing MA1032. The results of this pre and post testing might suggest specific interventions to help students who begin their MTU mathematics experience in Precalculus be more successful in Calculus I. 


\section{References}

ACT. (2015). The condition of STEM 2015. Retrieved from

http://www.act.org/content/act/en/research/condition-of-stem-2015.html

ACT. (n.d.). ACT College Readiness Benchmarks. Retrieved from

https://www.act.org/content/act/en/education-and-career-planning/college-and-career$\underline{\text { readiness-standards/benchmarks.html }}$

Adaricheva, K., \& Assylbekov, Z. (2013). The implementation of the computer system ALEKS for placement in mathematical courses at Nazarbayev University. Retrieved from http://nur.nu.edu.kz/handle/123456789/1684

Agresti, A. (2007). An introduction to categorical data analysis (2nd ed.). Hoboken, NJ: John Wiley \& Sons, Inc.

ALEKS Corporation. (2016). ALEKS placement problem types. Retrieved from https://www.aleks.com/highered/ppl/ALEKS_Placement_Problem_Types.pdf

ALEKS Corporation. (n.d.-a). New PPL experience. Retrieved from https://www.aleks.com/highered/ppl/New_PPL_Experience

ALEKS Corporation. (n.d.-b). What is ALEKS PPL? Retrieved from https://www.aleks.com/highered/ppl/what_is_aleks_ppl

Bullock, D., \& Callahan, J. (2009). The implementation of an online mathematics placement exam and its effects on student success in precalculus and calculus. Paper presented at the 2009 American Society for Engineering Education Annual Conference \& Exposition, Austin, TX.

Carpenter, J., \& Hanna, R. (2006). Predicting student preparedness in calculus. Paper presented at the 2006 American Society for Engineering Education Annual Conference \& 62 
Exposition, Chicago, IL.

Falmagne, J.-C., \& Doble, C. (2013). Overview. In J.-C. Falmagne, D. Albert, C. Doble, D. Eppstein, \& X. Hu (Eds.), Knowledge spaces: Applications in education (pp. 3-26). Berlin Heidelberg: Springer.

Fields, R., \& Parsad, B. (2012). Tests and cut scores used for student placement in postsecondary education: Fall 2011. Retrieved from https://eric.ed.gov/?id=ED539918

Gardner, J., Pyke, P., Belcheir, M., \& Schrader, C. (2007). Testing our assumptions: Mathematics preparation and its role in engineering student success. Paper presented at the 2007 American Society for Engineering Education Annual Conference \& Exposition, Honolulu, HI.

Harper, M., \& Reddy, A. A. (2013). Detecting concepts crucial for success in mathematics courses from knowledge state-based placement data. Retrieved from https://arxiv.org/abs/1312.1127

Hsu, E., \& Bressoud, D. (2015). Placement and student performance in Calculus I. In D. Bressoud, V. Mesa, \& C. Rasmussen (Eds.), Insights and recommendations from the MAA national study of college calculus (pp. 59-67). Washington, DC: MAA Press.

Michigan Technological University. (n.d.). Math placement at Michigan Technological University. Retrieved from http://www.mtu.edu/math/placement/

Michigan Technological University Mathematical Sciences Department. (2015). Fall 2015 MA1161/1160 final exam.

Michigan Technological University Office of Institutional Analysis. (2016). 2015-2016 fact book. Retrieved from http://192.168.1.1:8181/http://www.admin.mtu.edu/ia/Fact Book/finalver2016.pdf 
R Core Team. (2016). R: A language and environment for statistical computing. Retrieved from https://www.R-project.org/

Reddy, A. A., \& Harper, M. (2013a). ALEKS-based placement at the University of Illinois. In J.C. Falmagne, D. Albert, C. Doble, D. Eppstein, \& X. Hu (Eds.), Knowledge spaces: Applications in education (pp. 51-68). Berlin Heidelberg: Springer.

Reddy, A. A., \& Harper, M. (2013b). Mathematics placement at the University of Illinois. PRIMUS: Problems, Resources, and Issues in Mathematics Undergraduate Studies, 23(8), 683-702.

Sonnet, G., and Philip M. Sadler. (2014). The impact of taking a college pre-calculus course on students' college calculus performance. International Journal of Mathematical Education in Science and Technology, 45, 1188-1207.

UC Regents and ALEKS Corporation. (2012). ALEKS higher education math placement. Retrieved from http://successinhighered.com/math/files/2014/09/ALEKS-Placement$\underline{\text { TOC.pdf }}$ 


\section{Appendix - Additional Contingency Tables for Chapter 6}

Table A1 is the contingency table for Midterm Exam 2 in Calculus I. Scores of $70 \%$ or higher were considered satisfactory. Nonzero scores less than $70 \%$ were considered unsatisfactory.

Table A1

Contingency Table for Calculus I Midterm Exam 2 Scores

\begin{tabular}{lccr}
\hline Group & Satisfactory & Unsatisfactory & Total \\
\hline 1: Calculus I in Fall 2015, 1 ALEKS test attempt & 196 & 62 & 258 \\
$\begin{array}{l}\text { 2: Calculus I in Fall 2015, 2 or 3 ALEKS test attempts, } \\
\text { retake necessary for Calculus I placement }\end{array}$ & 115 & 108 & 223 \\
$\begin{array}{l}\text { 3: Calculus I in Fall 2015, 2 or 3 ALEKS test attempts, } \\
\text { retake optional for Calculus I placement }\end{array}$ & 14 & 3 & 17 \\
$\begin{array}{l}\text { 4: Precalculus in Fall 2015, Calculus I in Spring 2016 } \\
\text { Total }\end{array}$ & 18 & 54 & 72 \\
\hline
\end{tabular}


Table A2 is the contingency table for Calculus I final exam scores. Scores of $70 \%$ or higher were considered satisfactory. Nonzero scores less than $70 \%$ were considered unsatisfactory.

Table A2

Contingency Table for Calculus I Final Exam Scores

\begin{tabular}{lccr}
\hline Group & Satisfactory & Unsatisfactory & Total \\
\hline $\begin{array}{l}\text { 1: Calculus I in Fall 2015, 1 ALEKS test attempt } \\
\text { 2: Calculus I in Fall 2015, 2 or 3 ALEKS test attempts, } \\
\text { retake necessary for Calculus I placement }\end{array}$ & 123 & 131 & 254 \\
$\begin{array}{l}\text { 3: Calculus I in Fall 2015, 2 or 3 ALEKS test attempts, } \\
\text { retake optional for Calculus I placement }\end{array}$ & 11 & 153 & 215 \\
$\begin{array}{l}\text { 4: Precalculus in Fall 2015, Calculus I in Spring 2016 } \\
\text { Total }\end{array}$ & 14 & 6 & 17 \\
\hline
\end{tabular}


Table A3 is the contingency table for Calculus I final course grades. Grades of A, AB, B, BC, or C were considered satisfactory. Grades of CD, D, or F were considered unsatisfactory.

Table A3

Contingency Table for Calculus I Final Course Grades

\begin{tabular}{cccc}
\hline Group & Satisfactory & Unsatisfactory & Total \\
\hline 1: Calculus I in Fall 2015, 1 ALEKS test attempt & 207 & 49 & 256 \\
$\begin{array}{l}\text { 2: Calculus I in Fall 2015, 2 or 3 ALEKS test attempts, } \\
\text { retake necessary for Calculus I placement }\end{array}$ & 129 & 91 & 220 \\
$\begin{array}{l}\text { 3: Calculus I in Fall 2015, 2 or 3 ALEKS test attempts, } \\
\text { retake optional for Calculus I placement }\end{array}$ & 15 & 2 & 17 \\
4: Precalculus in Fall 2015, Calculus I in Spring 2016 & 34 & 48 & 82 \\
Total & 385 & 190 & 575 \\
\hline
\end{tabular}

